Evaluation of GSA Maintenance Practices of Large Centrifugal Chillers and Review of GSA Refrigerant Management Practices

James Y. Kao

Building and Fire Research Laboratory Gaithersburg, Maryland 20899

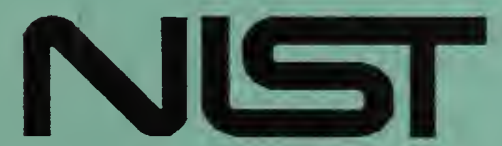

United States Department of Commerce Technology Administration

National Institute of Standards and Technology

QC 100

.056 



\section{Evaluation of GSA Maintenance Practices of Large Centrifugal Chillers and Review of GSA Refrigerant Management Practices}

James Y. Kao

Building Environment Division

Building \& Fire Research Laboratory

\section{January 1994}

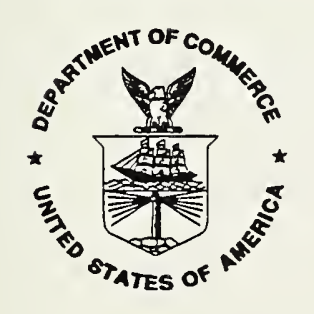

U.S. Department of Commerce

Ronald H. Brown, Secretary

Technology Administration

Mary L. Good, Under Secretary for Technology

National Institute of Standards and Technology

Arati Prabhakar, Director
Prepared for:

General Services Administration Roger W. Johnson, Administrator

Public Building Service

Kenneth R. Kimbrough, Commissioner

Office of Real Property Management \& Safety

Washington, DC 20405 



\section{Abstract}

This study contains two major subjects involving maintenance of large centrifugal chillers in the General Services Administration (GSA) facilities. The first part is to use nondestructive testing (NDT) techniques for chiller testing and maintenance. NDT techniques investigated are visual inspection, leak testing, vibration analysis, infrared thermal testing, eddy current testing, oil analysis, and acoustic emission testing. With the exception of acoustic emission testing, all other techniques are recommended for GSA chiller maintenance. The second part of this study is about refrigerant management. It reviews the Clean Air Act, Environmental Protection Agency regulations, a recently issued Executive Order, and Standards from the American Society of Heating, Refrigerating, Air Conditioning Engineers on subjects associated with ozone depleting refrigerants. Also reviewed are GSA refrigerant handling practices and certain GSA retrofit specifications involving these refrigerants. Recommendations are made for refrigerant management including chiller retrofit/conversion. 



\section{Acknowledgement}

This project is sponsored by the Office of Real Property Management and Safety, Public Building Service, General Services Administration. The project was initiated by John Iaconis, Chief, Buildings Maintenance Branch. Project managers are Steve McGibney and Wayne Daniels. 


\section{Table of Contents}

Abstract

Acknowledgement

1. INTRODUCTION.

2. EVALUATION OF GSA MAINTENANCE PRACTICES OF LARGE CENTRIFUGAL CHILLERS. . . . . . . . . . . . . . . . . . . . . . . . . . . . . 2

2.1 Current GSA maintenance practices. . . . . . . . . . . . . 2

2.1.1 General. . . . . . . . . . . . . . . . . . . . . . . . 2

2.1.2 Maintenance practices may vary from Region to Region. . . . . . . . . . . . . . . . . . 3

2.2 Using nondestructive testing techniques in chiller maintenance. . . . . . . . . . . . . . . . . . . 3

2.2.1 General. . . . . . . . . . . . . . . . . . 3

2.2.2 Visual inspection. . . . . . . . . . . . . . 3

2.2.3 Leak testing. . . . . . . . . . . . . . . . . . . . . 4

2.2.4 Vibration analysis. . . . . . . . . . . . . . . . . 5

2.2.5 Infrared thermal testing. . . . . . . . . . . . . . . 7

2.2.6 Eddy current (electromagnetic) testing. . . . . . . . 8

2.2.7 Oil analysis. . . . . . . . . . . . . . . . . . . . . 9

2.2.7.1 Moisture content. . . . . . . . . . . . . . 9

2.2.7.2 0il acidity. . . . . . . . . . . . . . 10

2.2.7.3 Chiller wear. . . . . . . . . . . . . 10

2.2.8 Motor and associated electrical equipment testing. . . 11

2.2.9 Acoustic emission. . . . . . . . . . . . . . . . . 11

2.3 Calibration of instruments. . . . . . . . . . . . . . . . 12

2.4 Data trending. . . . . . . . . . . . . . . . . . . . . . . . 12

2.5 Maintenance administration. . . . . . . . . . . . . . . 13

3. REVIEW OF GSA REFRIGERANT MANAGEMENT PRACTICES. . . . . . . . . . . . 14

3.1 Background on ozone depletion refrigerants. . . . . . . . . . . 14

3.2 Clean Air Act and EPA regulations. . . . . . . . . . . . . . . 15

3.2.1 Recycling regulations. . . . . . . . . . . . . . 16

3.2.1.1 Prohibition on venting. . . . . . . . . . . . 16

3.2.1.2 Recovery and recycling equipment. . . . . . 17

3.2.1.3 Required practices. . . . . . . . . . . . 17

3.2.2 Labeling regulations. . . . . . . . . . . . . . . . . 19

3.2.3 Used oil from refrigeration equipment. . . . . . . . . 19

3.2.4 Federal Procurement. . . . . . . . . . . . . . . 20

3.3 Executive Order 12843, Procurement Requirements and Policies
for Federal Agencies for Ozone-Depleting Substances. . . . . 20

3.4 ASHRAE recommended practices. . . . . . . . . . . . . . . . . 20

3.4.1 Safety. . . . . . . . . . . . . . . . . . . 20

3.4.2 Reduction of refrigerant emission. . . . . . . . . . . 22

3.5 Assessment of current GSA refrigerant handling practices. . . 23 
3.5.1 Chiller inventory. . . . . . . . . . . . . . . . . . . 24

3.5.2 Operations and maintenance practices. . . . . . . . . 24

3.5.3 Refrigerant containment. . . . . . . . . . . . . . . 25

3.5.4 Safety of personnel. . . . . . . . . . . . . . . . . 26

3.5.5 Refrigerant recovery, recycling, and reclamation. . . 26

3.5.6 Chiller repair or procurement. . . . . . . . . . . . 26

3.6 Refrigerant handling recommendations. . . . . . . . . . . . . 27

3.6.1 Chiller retrofit. . . . . . . . . . . . . . . . 29

3.6.2 Chiller conversion. . . . . . . . . . . . . . 30

3.6.3 New chiller procurement. . . . . . . . . . . . . . 30

3.6.4 Chiller room survey and update. . . . . . . . . . . . 30

3.6.5 Education and certification program for operation and maintenance personnel. . . . . . . . . . . . . . . . 30

3.6.6 Procurement of recovery and recycling equipment. . . . 30

3.6.7 Refrigerant record keeping program. . . . . . . . . . 30

3.7 Assessment of GSA "CFC SPECIFICATION". . . . . . . . . . . . . 31

4. SUMMARY OF RECOMMENDATIONS. . . . . . . . . . . . . . . . . . . . . . 32

4.1 Large centrifugal chiller maintenance practices. . . . . . . . 32

4.2 Refrigerant management practices. . . . . . . . . . . . . . 34

REFERENCES. . . . . . . . . . . . . . . . . . . . . . . . . . . 37

APPENDIX A GSA Chiller Inventory Sample Printout . . . . . . . . . . . . A-1

APPENDIX B GSA "CFC SPECIFICATION" . . . . . . . . . . . . . . . . . B-I 



\section{INTRODUCTION.}

The National Institute of Standards and Technology (NIST) and the General Services Administration (GSA) effected an agreement of research and technology transfer service in September 1993 stipulating that NIST conduct an evaluation of GSA's current practices of maintenance of large centrifugal chillers with special emphasis on using nondestructive testing (NDT) techniques. NIST is also to review GSA's Refrigerant Management Plan and general maintenance practices in reducing ozone-depleting refrigerants for compliance to Environmental Protection Agency (EPA) Regulations under the Clean Air Act. NIST received the following documents from GSA at the onset of the project: computer printouts listing GSA's chiller inventory, a Building Maintenance Management Handbook (PBS P 5850.1B dated October 8, 1981), a Refrigerant Management Plan (dated September, 1992), a copy titled "CFC SPECIFICATION" (undated) which is used in GSA maintenance contracts, a copy of the Clean Air Act Amendment of 1990, and a draft copy of EPA regulation " 40 CFR Part 82, Protection of Stratospheric Ozone" which has since been replaced by the final regulation. The specific objectives of this project are twofold: to evaluate and utilize modern predictive maintenance techniques using available diagnostic and analytical equipment as a supplement or replacement to current calendar-based preventive maintenance procedures; and to reduce the loss and the risk of loss of ozone-depleting refrigerants by centrifugal chillers through equipment modifications and operational and maintenance practices. In this report, these two subjects (i.e. chiller maintenance and refrigerant handling) are presented separately. However, in many respects they are closely interrelated and should be considered together in chiller operation and maintenance programs and practices. 
2. EVALUATION OF GSA MAINTENANCE PRACTICES OF LARGE CENTRIFUGAL CHILLERS

\section{EVALUATION OF GSA MAINTENANCE PRACTICES OF IARGE CENTRIFUGAL CHILLERS.}

\subsection{Current GSA maintenance practices.}

2.1.1 General. The total cooling capacity of GSA managed facilities is approximately $16,000 \mathrm{~kW}$ (450,000 refrigeration tons). Although GSA's chiller inventory printouts do not categorize the type of chillers (i.e. centrifugal, absorption, reciprocating, etc.), examination of the listed models reveals that the major part of GSA's cooling capacity is provided by centrifugal chillers. Administratively, GSA divides its facility management into ten regions. All regions use the same basic guidelines for equipment maintenance. Specific maintenance practices may vary from region to region and from facility to facility.

GSA preventive maintenance procedures are specified in Appendix $J$ of Preventive Maintenance Guides in the GSA Building Maintenance Management Handbook PBS P5050.1B. Appendix J contains preventive maintenance guides (PM guides), also known as "Guide Cards", for various pieces of equipment (e.g. air handler units, boilers, etc.). Each PM guide enumerates necessary tools and materials, lists special instructions, and requires maintenance items to be performed (referred to as "Check Points" on the guides). The required frequency of maintenance services (e.g. quarterly, annual) is also given on the PM guide. PM guides are updated periodically. The preventive maintenance requirements for centrifugal chillers and related equipment are included on PM guides R-5 (labeled as Refrigeration Machine (Centrifugal and Reciprocating)), R-6 (Refrigeration Controls Central System), R-13 (Non destructive Chiller Tube Analysis), M-3 (Motors), M-10 (Motor Controller Unit (2200 volts and above and 200 HP and above)), M-11 (Motors, Induction, Synchronous, and Wound Rotor (600 volts and above or $200 \mathrm{HP}$ and above), E-20 Induction Disc over Current Relay), E-22 (Thermal Over Current Relay), E-23 (Induction Disc - Directional Over Current Relay), and E-28 (Motor Starters, $100 \mathrm{HP}$ and Up).

The Check Points in PM guides give fairly brief but generally adequate descriptions of maintenance requirements. Improvements may be made on certain PM guides. For example, one Check Point states: "check and correct alignment of drive couplings" of chillers. The PM guide that includes this Check Point may be enhanced by adding the techniques of checking and correcting alignment of drive couplings, as well as the recommended instruments to be employed. Similarly, descriptions of operating purge units may be expanded so that the operation of purge units can be integrated as a preventive maintenance tool. Also, PM guides for other unlisted techniques such as vibration analysis and compressor oil analysis, should be added. Finally, methods of predictive maintenance are absent in the Handbook. Chiller condition trends should be plotted with the periodically-collected operating and maintenance data, providing the maintenance personnel a tool to judge when major services and replacement of parts should take place. 
2.1.2 Maintenance practices may vary from Region to Region. Under current GSA practices, GSA regions have the flexibility of administering maintenance procedures differently, such as using pilot projects in small scale within a region to try out certain maintenance procedures, before they are implemented region-wide. Thus, chiller maintenance practices may vary from region to region and from building to building. One may find that certain maintenance procedures are practiced in some Regions or buildings but not in others. However, all maintenance offices follow the procedures of the PM guides as minimum requirements.

\section{maintenance. \\ 2.2 Using nondestructive testing techniques in chiller}

2.2.1 General. Nondestructive testing are comprised of a wide range of techniques to detect machinery conditions and flaws without incurring damage to the machinery evaluated. Many of these techniques are used for identifying material flaws but are not applicable technically or economically in the subject of this study. Several NDT techniques were examined for possible use in preventive maintenance of centrifugal chillers. They include acoustic emission, eddy current testing, infrared application, leak detection, oil analysis, vibration analysis, and ultrasonic examination. Not all the examined techniques are suitable for testing centrifugal chillers. Of those that are suitable, some are only alternatives for other better suited techniques. Several of these techniques are currently being used by GSA. When NDT techniques are appropriately used, their benefits of enhancing chiller performance and reliability may be substantial. They not only can detect operating faults, but also save chiller operating energy, eliminate unnecessary services, and prevent unexpected breakdowns and interruptions to building occupancy. The following sections briefly discuss NDT techniques that NIST investigated and the applicability of these techniques in GSA chiller maintenance program. Comments related to current GSA maintenance practices are also discussed.

2.2.2 Visual inspection. Visual inspection is classified as one of the NDT inspection techniques. The requirement of visual inspection is fundamental and is used in daily operation and maintenance of all building equipment. Although it is the simplest and most basic method in building operation and maintenance, it is probably the most important one. The majority of defects found in equipment operation are usually discovered by visual inspections. Visual inspections for centrifugal chillers are generally assisted by instruments such as thermometers, pressure gauges, meters, and other indicating instruments, and are for the most part integrated into daily system operations. GSA has a form (Refrigeration Operating Record, Form 480) for recording chiller operation conditions. The operating personnel on duty uses the form to record a complete set of chiller conditions every two hours. Data to be recorded include conditions of evaporator and condenser (for both refrigerant and water sides), compressor operating conditions (operating capacity, bearing temperature, and oil pressure), motor amperage, auxiliary equipment (purge unit, if installed, and oil pumping system). The data recorded on this form will give 
a complete snapshot of the running conditions of the chiller. NIST recommends adding requirements to record purge unit accumulated running time, as well as the amount of purged water volume on this form. Long term data recorded by using this form (e.g. monthly, or quarterly) are used to predict certain maintenance needs. Long term record analysis will be discussed further in the Section on predictive maintenance. Other visual inspections include inspection of structural integrity of chiller components and observation of chiller operating abnormalities. Magnifying glasses are useful tools to assist in this effort.

Lighting obviously is an important consideration for visual inspection. Light intensity, diffusion (shadow), direction (glaring), and wavelength (color) are important factors to be considered. A one-time general survey of lighting conditions in the mechanical rooms where chiller routine maintenance is performed (reading thermometers, gauges, and other data collecting and observing locations) should be conducted. If unsatisfactory conditions are discovered, they should be corrected. Using flash lights for the purpose of equipment operation and maintenance are not a substitute for adequate permanent lighting.

Visual inspection with infrared instruments to detect thermal insulation defects and uneven temperature (hot spots) in motors and other chiller components is discussed in section 2.2.5.

2.2.3 Leak testing. Leak testing is also classified in NDT as a typical evaluation tool. There are many standard methods of leak testing, ranging from simple bubble testing to very sophisticated methods using gas chromatographies and mass spectrometers. In the refrigeration industry, bubble testing and halogen detectors are used to locate specific leak sites, while the pressure method is used to verify overall chiller tightness. These techniques are well developed and have served their functions and objectives well. In the GSA Building Maintenance Management Handbook, the only related requirement is to "use oil-dry nitrogen to test for leaks per manufacturer's instructions", and the procedures for applying these techniques are not discussed. Presumably this is due to the facts that (1) chiller manufacturers have detailed instructions for leak testing; and (2) that leak testing is done routinely. However, it will be useful to set unified minimum chiller maintenance requirements for leak testing by establishing generic procedure requirements in the Handbook (new PM guides in Appendix J). Standard charging procedures, triple evacuation (to below $466.6 \mathrm{~Pa}$ ( 3500 micron $\mathrm{Hg}$ absolute)) or deep vacuum (to below $133.3 \mathrm{~Pa}$ (1000 micron $\mathrm{Hg}$ absolute)), are also proven sound practices to be added to the cards.

The pressure method is performed by filling chillers with dry nitrogen to an appropriate pressure level (chiller dependent, follow manufacturer's recommendations) after preparation work is completed (including general inspection, draining condenser and evaporator shells, calibrating pressure gauges, etc.). The pressure level is then recorded. During this testing period, the space temperature should be kept fairly constant. After waiting at least 24 hours, the pressure gauge is read again. If the pressure of the chiller is kept within a set limit, the chiller has passed this test. Similar testing may be performed by applying vacuum instead of applying pressure. 
If the chiller does not pass the above test, the locations of the leaks must be found. Finding chiller leaks is done either by bubble testing which uses soapy solution, typically 1 part liquid detergent, 1 part glycerine and 4.5 parts water, at suspected leaky locations (seals, gaskets, fitting connections, and motor terminals); or by pressurizing chiller with a mixture of nitrogen and tracer gas R-22 (approximately 5\%, see chiller manufacturers' instructions) and locating leaks with halogen vapor detectors. Chillers may also leak at locations where heat exchanger tubes are connected to tube sheets. Air in the water boxes needs to be tested to determine the tube connection tightness (separation of refrigerant/water sides). During leak testing, the equipment room should be well ventilated for both possible contamination of halogen gas sensing and personnel safety. EPA permits using R-22 in this procedure for pressure testing purpose. Regulations on venting refrigerants is fully discussed in section 3.2.1.

Low pressure centrifugal chillers (using mainly R-11, 113 and 123) are usually provided with purge units to remove noncondensibles and moisture in the system. As alluded to previously, the running time of these units and the accumulated water from purging are indications of leak states of chillers under normal operation conditions, and are very useful tools for predictive maintenance purposes.

Chillers should be charged with refrigerants to the correct amount as recommended by the chiller manufacturers. Additional charges over time, either caused by leaking or purging, should be recorded. This record may be used as a tool for maintenance decision making (see section 2.4 ).

2.2.4 Vibration analysis. The current GSA maintenance procedures do not include vibration analysis as a standard technique for evaluating centrifugal chiller operating conditions. Vibration testing and analysis are useful in detecting chiller bearing, gear misalignment, and other dynamic problems. It is also useful in detecting and correcting imbalance of rotating parts of the centrifugal chiller. Severely unbalanced parts, such as motors and compressor rotors, if not corrected early, not only can cause damage to the parts themselves, it may also cause damage to other chiller components. Vibration and misalignment may also cause refrigerant leaks (see section 3.5 .3 ).

Vibration in centrifugal chillers is often caused by unbalanced motors or compressors, bent rotor or compressor shafts, misalignment of motor and compressor couplings, misalignment or incorrect clearance of gears, damaged or worn gears, misalignment of bearings, excessive bearing clearances, defective or worn bearings, or resonance. Vibration measuring and analyzing instruments use a variety of sensors (transducers, commonly called pickups) based on different principles to detect displacement, velocity, or acceleration at the chiller frame close to the components of concern. Vibration signals received by the sensors are converted and conditioned to proper electrical voltage outputs that represent the magnitude of the vibration. Velocity pickups are used to measure vibration displacement and velocity, and accelerometer pickups are used to measure acceleration. Selection of pickups is important. Brief descriptions of commonly used pickups are given below: 
Moving-coil seismic pickup. This pickup generates output signals by an electrical coil which moves in a magnetic field in the pickup housing. It is rugged in construction, has high output (therefore the effect from cable length is small), and does not require input power. Its sensitivity decreases at low frequencies, resulting in inaccurate amplitude readings below 600 cycles per minute (CPM). It can also be subjected to outside magnetic interference, since the pickup has a magnet in it to generate the vibration signals. Although the effect of outside magnetic fields may be reduced by adding shields or by using metal rods to transmit vibration remotely, using this type of pickups is not recommended for measuring large compressor motors which generate strong magnetic field. Frequency range for measurement is from approximately 600 to $60,000 \mathrm{CPM}$.

Moving-coil direct-prod pickup. This pickup is similar to moving-coil seismic pickup in operating principle except that it is light weight and it uses a prod to contact the vibrating object. This pickup can measure vibration at frequencies well below $600 \mathrm{CPM}$. It is also subject to outside magnetic interference. Frequency range for measurement is from approximately 50 to 60,000 CPM.

Piezoelectric velocity pickup. A piezoelectric device in the pickup generates electric signal when vibration causes stress in the piezoelectric material. The signal is weak and must be amplified to be useful. Since amplifiers are used, signals can be transmitted through long cables. Frequency range for measurement is from approximately 60 to over 250,000 CPM.

Accelerometer. This pickup uses the same principal as the piezoelectric velocity pickup. It usually has a built-in amplifier in the pickup. The force generated by vibration is transduced to a voltage which is proportional to the acceleration of the vibration. It is suitable for use in analyzing high frequency vibrations such as for gears and bearings (ball or roller). Since it is not sensitive to outside magnetic interference, it is also suitable for large motor applications. Frequency range for measurement is from approximately 600 to $600,000 \mathrm{CPM}$.

In selecting vibration pickups for preventive maintenance, consider output sensitivity, possible frequency range of the component vibration, external interference, and vibration parameter to be monitored (displacement, velocity, or acceleration). In general, accelerometers are suitable for gear boxes and bearings (ball or roller) for possible high frequency vibration. One of the velocity type (moving-coil direct-prod or piezoelectric) pickups will be proper for checking compressor motor imbalance and vibration caused by too large sleeve bearing clearance (low frequency vibration). Two vibration readings with pickups at the horizontal and the vertical positions of the rotating element, and one reading along the rotating element's axial direction are usually needed to know the conditions of concerned component (e.g. bearing).

The vibration signals from a pickup are fed into a meter, recorder, or analyzer. Vibration meters are very portable and simple to use. Some more sophisticated meters have filters so that the desired spectrums can be isolated. They may also 
have features to change from velocity readings to displacement or acceleration readings by users. Recorders can transfer vibration data taken in the field to a computer for analysis. Analyzers are much more sophisticated than meters and are capable of using Fast Fourier Transform (FFT) technique to break down a complex vibration signature into different frequency components for analysis. They also have the capability of on-line data analysis. Vibration data (amplitude, velocity or acceleration) may be plotted against frequency or time. Limits of vibration parameters may be preset so that decisions can be made to initiate preventive or predictive maintenance procedures. Commercial software programs are available for data analysis.

Centrifugal chillers have multiple rotating components which each generates vibration individually. The vibration signatures obtained from testing often contain combined effects of more than one component. Data interpretation skills and experience of personnel are very important. Highly trained and experienced persons are usually required. It is also important that chillers are tested for vibration and records are kept when they are new or are just overhauled, so that baseline data can be used for future comparison and analysis. The frequency of vibration tests depend on machine conditions and the history of vibration changes. Initially, vibration data should be taken every one to two months.

2.2.5 Infrared thermal testing. The current GSA maintenance procedures do not require using the infrared thermographic technique in centrifugal chiller testing. This technique may be applied in two areas: (1) to check thermal insulation on chillers and associated piping for damages and void spaces; and (2) to detect degradation and excessive heat generation of electrical components and wire connections (compressor motors and associated starter parts and panels) for "hot spots".

All infrared thermal instruments use infrared sensitive elements to detect the electromagnetic wave emitted from the equipment surface and are performed from a distance to the equipment. The output from the sensing devices can be conditioned and manipulated to show data on monitor screens or recorded on films or magnetic media for analysis. The response time is short allowing fast scanning for a large target area. Various principles and materials are used in sensing and measuring the effect of radiation (photon effect, thermal sensing, gas cells, etc.). Some instruments require liquid gas (e.g. nitrogen) to cool sensors in order to achieve good sensitivity range. With the aid of a black body radiator with known temperatures, infrared thermal instruments can be calibrated and accurate temperature measurements can be readily accomplished. There are basically two categories of infrared thermal testings: thermography which maps the isotherms of the surface of an object, and thermometry which measures the surface temperature at a specific point of the object. The elaborate and more expansive method of thermography is not recommended in GSA chiller maintenance. This is due to the facts that (1) the objective of using infrared instruments on centrifugal chillers is to spot the temperature irregularities (insulation flaws and electrical equipment "hot spots"), not necessarily to know the accurate temperature at these locations; (2) the defects are usually repaired immediately; and (3) there is no need to keep the test results (temperature maps, data 
records) permanently (Although repair record should be recorded in chiller repair books or log forms). Instead, GSA should use thermometry instruments as their NDT evaluation tools for the purposes just discussed.

The selection of infrared thermometry instrument, in general, depends on the temperature ranges of the objects to be measured. For low temperature ranges, such as the application to chillers and electrical panels, thermometers that can respond to long wavelength in the ranges of 8 to 14 micrometers should be chosen. As expressed in Stefan-Boltzmann law and Kirchhoff's law in radiation, the infrared radiation intensity from any object is determined by the temperature of the object and its emissivity $\left(E=\epsilon \sigma T^{4}\right.$, where $E$ is the emissive power, $\epsilon$ is the emissivity of the surface, $\sigma$ is a constant, and $T$ is the absolute temperature of the object). The emissivity of a surface depends on the surface conditions and is a function of the wavelength. In general, a surface with low emissivity, such as polished metals, will give large errors ( $\epsilon$ is much smaller than unity). Since it is highly reflective, the test readings will also be affected by thermal radiation from other objects in the surroundings. Better infrared thermometry units have an emissivity adjustment feature to be adjusted by users to match the surface conditions to be tested. In measuring the temperature of chiller surfaces and electrical panels, knowing their surface emissivities may assist in obtaining more accurate readings. Tables of typical emissivity values of commonly encountered materials are readily available in books dealing with thermal radiation. A typical value for painted surfaces is approximately 0.95 at room temperature. Even without correcting for emissivity values, using infrared thermal instruments for these maintenance purposes is still valid. These tests are not conducted to find out the true temperatures of the objects, but to find the relative temperature differences on surfaces, so that the concerned flaws may be spotted. It should be noted that infrared thermal instruments are also useful in checking anomalies of other plant equipment (e.g. cooling of electric transformers).

2.2.6 Eddy current (electromagnetic) testing. GSA put into effect a requirement for eddy current tube testing recently (PM guide R-13 Non-Destructive Chiller Tube Analysis, effective March, 1993) with a testing frequency of once every three years. The test procedure calls for following the procedures of the American Society of Mechanical Engineers (ASME) Boiler and Pressure Vessel Code Section V, Nondestructive Examination, Article 8, Eddy Current Examination of Tubular Products.

Using eddy current testing on nonferromagnetic tubes has become a standard procedure in evaluating copper heat exchanger surfaces of chillers and other heat exchangers. It is used to detect surface and near-surface defects such as cracks, wears, pittings, and other discontinuities. These discontinuities are usually caused by corrosion (tube outside corrosion caused by acids in the refrigerant and galvanic reaction; and tube inside pitting caused by scale movement and improper cleaning), erosion, thermal stress (freezing), fatigue, support wear, and defects during the manufacturing process. The results of the test are useful in determining if defective chiller tubes should be replaced or temporarily plugged. Replaced tubes should be examined and cross-sectionally 
cut, if necessary, to determine the causes of defects.

An electrical coil probe which generates an electromagnetic field with alternating current is placed in the heat exchanger tubes, and eddy currents are induced in the tubes. The currents induced vary with the electrical conductivity of the tube. Any variation in tube material, dimension, and irregularities will change the electromagnetic responses and can be detected with an instrument. The depth of the inspection of the tube material may be adjusted by varying the frequency of energizing current (down to $0.5 \mathrm{kHz}$ ). Although the depth of penetration to detect flaws by eddy current technique is limited (ASTM Standard E 243, Standard Practice for Electromagnetic Examination of Copper and CopperAlloy Tubes limits tube wall thickness to $3 \mathrm{~mm}(0.12 \mathrm{in.})$ ), it is not a problem for centrifugal chiller tubes (most centrifugal chiller tubes have a thickness of approximately $0.9 \mathrm{~mm}(0.035 \mathrm{in.}))$. For heating, ventilating, and air conditioning (HVAC) applications, portable instruments are used for testing of heat exchanger tubes in the field. Test results are monitored with a scope and test data can be recorded automatically for later analysis. A standard calibration tube of the same construction and material as the chiller tube is used to establish system responses (known defects to instrument outputs) for comparison of test results. Calibration should be checked at the start of the test and at periodic interval during the test (e.g. every hour). If background noise and electrical interference are present, calibration should be checked more often.

2.2.7 Oil analysis. The current GSA PM guide R-5 (effective March, 1993) requires that the oil be replaced annually and the used oil be analyzed to determine bearing conditions. However, if a good oil analysis procedure is instituted, it is not necessary to replace oil at fixed time intervals, and more information on the chiller conditions may be acquired.

Depending on chiller make and design, oil under pressure is used to lubricate compressor bearings, motor bearings, and gears. Since oil is in close contact with the refrigerant, oil analysis can reveal a great deal of chiller conditions and can be used as a nondestructive diagnostic tool. (This analysis is very similar to a blood test for diagnosing human health.) It is important that when repairing or overhauling of a chiller is completed and its oil is replaced, the oil sump must be thoroughly cleaned before new oil is added, so that residues of the old oil will not contaminate the system and give false readings in future analysis. It is also important that oil sample taken for analysis be drawn from a location which can represent the bulk of the oil (i.e. not from a stagnant location). Air-Conditioning and Refrigeration Institute (ARI) Standard 700-1988, Specifications for Fluorocarbon Refrigerants, lists physical properties and recommended maximum contaminants for fluorocarbon refrigerants used in refrigerating and air conditioning products. Three basic objectives of oil analysis are to find the moisture content in the oil, the acidity of the oil, and the wearing conditions of chiller components.

2.2.7.1 Moisture content. ARI Standard 700-1988 recommends 10 ppm maximum water content by weight for new or reclaimed refrigerants. Up 
to $50 \mathrm{ppm}$ in oil samples taken from centrifugal chillers is considered normal. It is also normal to see higher moisture contents in samples taken in the summer when seasonal data are compared. If the moisture content is over $50 \mathrm{ppm}$, it indicates air leaks (for low pressure chillers) or heat exchanger tube leaks.

2.2.7.2 Oil acidity. The acidity test uses the titration principle to detect any compound that ionizes as an acid. ARI Standard 700-1988 recommends a maximum acidity of $1 \mathrm{ppm}$ by weight for new or reclaimed refrigerants. Acids in oil may be caused by oxidation of oil during normal aging process and high temperature, and the degradation of refrigerants. The acceptable acidity level depend on the oil being used in the chillers. The chiller manufacturer should be contacted.

2.2.7.3 Chiller wear. Trace amount of metals in the oil could be metal oxides formed from moisture in the oil, or it may indicate the wearing conditions of chiller components. The kind of metal depends on the material used in those components. Since materials used in chiller components may differ from manufacturer to manufacturer, there may not be set limits on the test results to indicate possible problems. A history of test data of the same chiller is useful in judging the chiller conditions (see later discussion on predictive maintenance). Commonly found metals in oil analysis and a general discussion are given below:

Aluminum. Usually found in low range. When higher levels are found, it may be from aluminum oxide or may indicates compressor impeller wear. Certain centrifugal chillers also use aluminum alloys in their bearings.

Chromium. Usually found in low range. When higher levels are found, this indicates shaft wear on rechromed shafts.

Copper. Corrosion causes high copper level in oil. If the copper levels are suspected high, acid and iron levels should be reviewed for confirmation.

Iron. Similar to high copper level discussed above. For chillers using gears (compressor speed is higher than motor speed), high iron levels also indicate gear wear.

Lead. Usually found in low range. High levels indicate corrosion of lead in lead based solder.

Tin. Many compressors use babbitt metal, which contains high content of tin, for their bearing material. When high levels of tin are found, this usually indicates wear of bearings. The change of tin content are rapid when bearing wear occurs. If bearing wear is suspected, oil analysis for tin should be performed within a month and the results compared. Corrosion from acid may also cause high tin levels. Therefore, acid levels should also be compared.

Silicon. Silicon indicates possible leakage of silica gel from silica gel type dehydrator cartridges, or dirt in system. 
Zinc. Some chiller parts in contact with refrigerant may be galvanized (e.g. eliminators in the evaporator) or may use zinc during manufacturing process. Refrigerants, then, may carry zinc in the oil system. Zinc may also come from additives in oil. In the latter case, the normal level of zinc should be known from manufacturers. Oil analysis should make a distinction between the two sources.

2.2.8 Motor and associated electrical equipment testing. GSA has detailed NDT test requirements for electrical motors and their associated electrical equipment. For motors in general, requirements include checking of imbalance of electrical resistance among windings, checking of imbalance of total inductance with phase inductances, checking winding electrical insulation, capacitance imbalance checks, power factor checks, and running amperage checks against nameplate ratings. For large compressor motors ( 600 volts and above or $149.2 \mathrm{~kW}$ (200 HP) and above), dielectric absorption or polarization tests are performed for all windings. Special requirements are also given for synchronous and wound rotor motors. For motor controllers and starters, requirements include checking motor current ratings against controllers' recommended current overload settings or heater sizes, performing time/current characteristics tests including overload trip testing, and checking contact resistances. General housekeeping maintenance includes cleaning motor body and ventilation ports, checking safety features, inspecting motor lubrication and supports, checking wiring and contact conditions, calibrating meters, etc. Most chiller and associated system controls are system dependent. It is generally required to test these systems following instructions of chiller manufacturers and project designs.

The required frequency of maintenance for motor starters over $75 \mathrm{~kW}$ (100 horsepower) (PM guide E-28) should be reviewed and reconciled. The three year frequency specified is quite different from what is required (one year) for chillers, compressor motors, and other motor controllers. Improvements may also be made by adding "Special Instructions" and "Check Points" for items especially pertaining to hermetic chillers, since many of GSA's centrifugal chillers are in this category. For example, if hermetic motor terminals or windings are contaminated (not cleaned properly), motor test readings may indicate low electrical resistance (megohms). Warnings about not to apply a higher voltage on motors than the motor nameplate ratings, or not to apply over 50 volts to motor windings while the motor is under vacuum should also be listed. As discussed previously under infrared thermal testing, infrared thermometry tests should be added to check motor starters and controllers for abnormal heating.

2.2.9 Acoustic emission. In general, any mechanical equipment with a characteristic acoustic signature may be tested with this technique. Acoustic emission is often used to detect cracks of structures caused by stress. When a structure crack is in progress, the process generates mechanical vibration to release energy in the material. This process may be transient or continuous. Sensing devices are attached to the structure at various locations to detect the acoustic waves emitted from the crack site. Another application, to a much less degree, is to detect leaks of storage tanks and pressure vessels. A leaky vessel under pressure will generate sound which can be detected by instruments. In 
theory, this technique may be used to test refrigerant leaks in centrifugal chillers. In practice, it has not been widely used mainly because better methods are available (simpler and more sensitive, see section 2.2.3 Leak Testing). Therefore, this technique is not recommended in GSA chiller maintenance.

2.3 Calibration of instruments. The current GSA requirements of calibrating measurement instruments are very few and inadequate. Accuracies of all instruments are subject to change due to storage conditions, misuse and mishandling, and the unstable nature of the materials used in the instruments. Although precision measurement work is generally not required in plant maintenance, the general tendency of most maintenance personnel is to trust whatever data are indicated on the instruments. NIST recommends that instrument calibration topics be strengthened in the Building Maintenance Management Handbook. These topics need not go into details of calibration procedures for all instruments used in maintenance. In fact, because calibration of precision instruments requires very special skills and knowledge, it is not appropriate to assign calibration burden to chiller maintenance personnel and their organizations. Except for very simple instruments, such as pressure gauges and thermometers, calibration should be contracted to instrument manufacturers and calibration laboratories.

In principle, field calibration involves comparing measurement readings of the instrument to be calibrated with the readings of a standard instrument. At least two points in the measurement range should be compared during calibration. If the field instrument has calibration adjusting features, the instrument should be adjusted after calibration. Otherwise, a calibration curve can be constructed by plotting the readings of the two instruments on an X-Y graph paper and future instrument readings are adjusted with the aid of the calibration curve. Good sources of measurement media (e.g. temperature bath, ice point Dewar vessel, steady pressure source) are needed for accurate calibration.

2.4 Data trending. The current GSA maintenance procedures do not explicitly include trending as a maintenance tool. Most PM guides specify a required maintenance frequency (mostly at one year intervals for centrifugal. chillers). This is consistent with the operational cycles of most centrifugal chillers, since most chillers are operated during the cooling seasons only. It is natural to perform major maintenance once a year during the noncooling period (this includes avoiding shutting down of chillers during the cooling season). However, time and materials may be saved if maintenance is performed only when needed. Using NDT data to trend chiller conditions is ideal for rendering judgement on applying predictive maintenance. Eddy current tube testing, vibration analysis, electrical insulation testing, and oil analysis are all suitable for this purpose. It is useful to collect and keep test data from a major overhauling of a chiller (for the case of oil analysis, keep test data from an oil change). Data history of the same parameter will be plotted against time so that the trend of change may be analyzed. A decision of maintenance then can be made from the trend of the history. Flexibility must be given to maintenance 
organization considering the overall cost of maintenance, available manpower for needed maintenance during cooling seasons, and the available spare capacity of the cooling plant. The possibility that a chiller must be shut down for maintenance during the cooling season exists. However, with reliable trend data and sound planning, untimely shut downs can be avoided.

2.5 Maintenance administration. As mentioned previously, GSA divides the country into ten regions administratively in facility operation, including maintenance of buildings. A large number of buildings in most regions, except the National Capital Region, are operated and maintained by private contractors. Both contractor and GSA personnel operated buildings follow the same maintenance procedures. In most cases, maintenance procedures which require special equipment and/or testing skills are contracted to specialty testing companies (e.g. eddy current testing, oil analysis) regardless of who is responsible for the maintenance. In the National Capital Region, GSA buildings are densely located and most buildings are operated and maintained by Government personnel. NIST recommends that GSA assemble pilot groups of specialty maintenance personnel, in-house or contracting, in selected areas to perform some of the NDT work for the following reasons: (1) centralized chiller data gathering and analysis by these groups may lead to better maintenance practices and the results can be evaluated for application nation-wide; (2) the benefit of these testing techniques can be applied to other HVAC equipment, not limited to centrifugal chillers; and (3) the high cost of testing equipment and personnel training are spread among many buildings. Specific NDT procedures included in this category are vibration analysis and eddy current tube testing. 


\section{REVIEW OF GSA REFRIGERANT MANAGEMENT PRACTICES.}

3.1 Background on ozone depletion refrigerants. Many of the currently used refrigerants in mechanical compression chillers contain chlorine atoms. When these refrigerants are released into the atmosphere, the chlorine atoms are eventually separated from the refrigerant and are combined with oxygen atoms of ozone molecules in the stratosphere. This process destroys the ozone layer and reduces the protection of the earth from ultraviolet radiation. The refrigerants which cause the most ozone depletion are chlorofluorocarbons (CFCs), such as R-11 and 12. The molecules of these refrigerants are very stable, so much of their chlorine is not released until they reach the stratosphere. Contributing to a much lesser degree to ozone depletion are hydrochloroflorocarbons (HCFC), such as R-22 and 123. Other ozone depletion refrigerants are azeotropes (mixtures) containing CFCs and HCFCs, such as R-500 (containing CFC-12 and HFC-152A) and 502 (containing HCFC-22 and CFC-115). A class of refrigerants known as HFCs, which contain only fluorine, carbon, and hydrogen, such as R-134a, have no ozone depletion potential (ODP). The historically-used refrigerant ammonia (R-717) also has no ODP. Intense research is being conducted to develop other refrigerants with no ODP.

In commercial buildings, the majority of cooling units are of the mechanical compression type. In low pressure centrifugal chillers, R-11 (CFC) is predominately used, while R-113 (CFC) is used to a much lesser degree. R-12 (CFC), R-114 (CFC), R-22 (HCFC), and R-500 (CFC azeotrope) are used in high pressure centrifugal and screw chillers. R-12 and R-22 are mainly used in reciprocating chillers. HCFCs, having much less ODP but facing eventual replacement, are considered as transitional refrigerants. Among HCFCs, R-123 is used in new low pressure centrifugal chillers and as a replacement in older low pressure chillers; R-22 is being used extensively in high pressure chillers. However, the HFC $\mathrm{R}-134 \mathrm{a}$ is intended to eventually replace $\mathrm{R}-22$ in new high pressure chillers. The following table lists average ODPs and boiling points of some commonly used halocarbon refrigerants in mechanical compression chillers. The ODP of R-11 is designated as 1.00 , and the ODPs of other refrigerants are determined relative to that of $\mathrm{R}-11$. (UNIT/WMO, 1989)

\begin{tabular}{|c|c|c|}
\hline $\begin{array}{l}\text { Halocarbon } \\
\text { Refrigerant }\end{array}$ & $\begin{array}{l}\text { Boiling Point } \\
\text { at } 1 \text { atm. } \\
{ }^{\circ} \mathrm{C} \quad{ }^{\circ} \mathrm{F}\end{array}$ & $\begin{array}{l}\text { Ozone } \\
\text { Depletion } \\
\text { Potential }\end{array}$ \\
\hline$\overline{R-11}$ & $23.8 \quad 74.9$ & 1.00 \\
\hline$R-12$ & $-29.8-21.6$ & 0.93 \\
\hline$R-22$ & $-40.8-41.4$ & 0.049 \\
\hline$R-113$ & $47.6 \quad 117.6$ & 0.83 \\
\hline$R-114$ & $\begin{array}{ll}3.8 & 38.8\end{array}$ & 0.71 \\
\hline$R-123$ & 27.6 & 0.017 \\
\hline$R-134 a$ & -24.8 & 0 \\
\hline
\end{tabular}


Following the current international agreements (Montreal Protocol in September 1987, London Amendment in June 1990, and Copenhagen Amendment in November 1992) and the U.S. Environmental Protection Agency (EPA) regulations, the production of CFCs (R-11, 12, etc.) is being decreased yearly and will be phased out entirely before January 1, 1996. The production of HCFCs (R-22, R-123, etc.) will be reduced starting in 1996 and will be phased out in 2020 for $R-22$ and all HCFCs in 2030. Centrifugal chiller manufacturers have taken different approaches in dealing with ozone depletion refrigerants. For example, one major U.S. manufacturer decided to phase out all sales of CFC chillers by the end of this year, and that all their new centrifugal chillers made after that date will be using R-134a only. Some other major chiller manufacturers are modifying low pressure centrifugal chiller production by replacing R-1l with $\mathrm{R}-123$ and by improving purging techniques and leak protection to reduce refrigerant losses. Other than thermodynamic and heat transfer properties of refrigerants (boiling temperature, latent heat of vaporization, critical point, conductivity, viscosity, etc.), toxicity, flammability, compatibility with lubricants, compatibility with materials of the equipment, and projected future cost and availability of refrigerants are factors which also influence refrigerant selection.

During the very recent past, the U.S. Environmental Protection Agency has issued numerous regulations regarding ODP substance uses. Standard organizations in the HVAC industry have also published standards and guidelines for refrigerant handling practices. The main thrusts of all these regulations and standards focus on using alternative refrigerants; reducing ODP substance emission; recovery, recycling, and reclaiming of used refrigerants; and refrigerantassociated safety issues. The current HVAC industry practices of operation and maintenance of refrigeration equipment, including those used by GSA personnel, generally follow these rules and recommendations. This report will review in detail these regulations and standards concerning refrigerant handling and will make recommendations on their applications to the operation and maintenance of GSA chiller facilities. However, it must be emphasized that the intense new development in refrigerant technology as well as possible frequent changes in governmental regulations due to these technological developments may alter the current outlook and practices of refrigerant-related issues. It is desirable for GSA to review their refrigerant handling practices periodically every two to three years.

3.2 Clean Air Act and EPA regulations. Title VI of the Clean Air Act Amendment of 1990 deals with stratospheric ozone protection. Section 602 of the Act separates ozone depletion substances into two classes: Class I includes CFCs and Class II includes HCFCs. Commonly used refrigerants listed under Class I include R-11, $-12,-113,-114$, and -115. Commonly used refrigerants listed under Class II include R-22 and -123. Section 603 provides requirements for the monitoring and reporting of ozone depletion substances. Sections 604, 605, and 606 consider phaseout of the production and consumption of Class I and Class II substances. Exchanges of production and consumption allowances of such substances are described in Section 607. Section 608 instructs EPA to establish 
requirements regarding the use and disposal of Class I and Class II substances during service, repair, or disposal of appliances. The requirements under this section include reducing the use and emission of such substances to the lowest achievable level, maximizing the recapture and recycling of such substances, removing such substances from appliances and machines before they are disposed of, preventing the release of such substances to the environment during the disposal process of appliances and machines, and prohibiting intentional venting of such substances to the environment. Section 610 prohibits nonessential use of CFCs. Section 611 requires labeling of containers of Classes I and II substances. Section 612 promotes the development and use of safe substitutes for Class I and class II substances. Section 613 requires that all Federal agencies' procurement regulations conform to this law, that the substitution of safe alternatives for Class I and Class II substances be maximized, and that certification upon conformation to be tendered to the President. Other sections of this law which are not related to chiller operations are not reviewed here.

3.2.1 Recycling regulations. Section 608 of the Clean Air Act has perhaps the greatest effect on chiller maintenance and refrigerant handing. EPA issued detailed regulations of recycling and emission reduction requirements, under Section 608, on May 14, 1993 (Title 40 Code of Federal Regulations (CFR) Part 82 - - Protection of Stratosphere Ozone, Subpart F - Recycling and Emissions Reduction). This subpart requires any person servicing, maintaining, or repairing building appliances containing class I and class II refrigerants to reduce emissions of these refrigerants to the lowest achievable level. This subpart also specifies requirements of persons disposing of such appliances, refrigerant reclaimers, appliance owners, and manufacturers of appliances and recycling and recovery equipment. In this document, EPA defines high pressure appliances as being those appliances using refrigerants with boiling points between -50 and $10^{\circ} \mathrm{C}$ ( -58 and $50{ }^{\circ} \mathrm{F}$ ), such as R-12, $-22,-114$, and -500 ; and low pressure appliances as being those appliances using refrigerants with boiling points above $10^{\circ} \mathrm{C}\left(50^{\circ} \mathrm{F}\right)$, such as $\mathrm{R}-11$, -113 , and -123 . The main regulations which concern building appliances and machines and may impact GSA operations in refrigerant handling are as follows:

3.2.1.1 Prohibition on venting. This rule is a statutory prohibition in the Clean Air Act and has been effective since July 1, 1992. The law prohibits individuals from knowingly venting ozone-depleting refrigerants into the atmosphere while maintaining, servicing, repairing, or disposing of air conditioning or refrigeration equipment. EPA, in their Final Rule Summary on recycling requirements (issued May 14, 1993) of Section 608, gives the following three exceptions:

a. "De minimis" amount of refrigerant released in the course of making a good faith attempt to recapture and recycle or safely dispose of refrigerant.

b. Refrigerant emitted in the course of normal equipment operation. Examples are leaks from seals of high pressure chiller operation and discharge of gas during purging of low pressure centrifugal chillers. 
c. The discharge of a mixture of nitrogen and $\mathrm{R}-22$ used as holding charges as leak test gases of chillers.

3.2.1.2 Recovery and recycling equipment. EPA has established a certification program for recovery and recycling equipment to be used in servicing refrigeration equipment. The required vacuum levels of the recovery and recycling equipment are categorized according to the refrigerant pressure and the amount of refrigerant charges of the equipment, and are grouped according to the time the recycling or recovery equipment is manufactured (before or after November 15, 1993). The following table lists the vacuum requirements for maintenance, service, or repair when refrigeration equipment are opened. The recovery and recycling equipment used for these purposes, therefore, must be certified to the vacuum levels accordingly.

Minimum Vacuum, relative to $101.325 \mathrm{kPa}(29.9$ in of $\mathrm{Hg})$

Refrigeration Equipment
HCFC-22, normally containing:

less than $91 \mathrm{~kg}$ (200 lbs)

$91 \mathrm{~kg}$ (200 lbs) or more

Other high pressure equipment (CFC-12,

$-500,-502,-114)$ normally containing:

less than $91 \mathrm{~kg}$ (200 lbs)

$91 \mathrm{~kg}$ (200 lbs) or more

Very high pressure (CFC-13, -503)

Low pressure (CFC-11, HCFC-123)
Equipment

manufactured

before $11 / 15 / 93$
Equipment manufactured after $11 / 15 / 93$

$\begin{array}{ll}0 \mathrm{~Pa}(0 \mathrm{in}) & 0 \mathrm{~Pa}(0 \mathrm{in}) \\ 13.5 \mathrm{kPa}(4 \mathrm{in}) & 33.9 \mathrm{kPa}(10 \mathrm{in})\end{array}$

$13.5 \mathrm{kPa}$ (4 in) $33.9 \mathrm{kPa}$ (10 in) $13.5 \mathrm{kPa}$ (4 in) $50.8 \mathrm{kPa}$ (15 in)

$0 \mathrm{~Pa}(0 \mathrm{in}) \quad 0 \mathrm{~Pa}$ (0 in)

$84.7 \mathrm{kPa}$ (25 in) $3.4 \mathrm{kPa}$ (1 in

$\mathrm{Hg}$ ) absolute

\subsubsection{Required practices.}

a. Recovery equipment. All persons opening refrigerant appliances (except for small appliances: see paragraph c. below for the definition of small appliances) for purposes of maintenance, service, or repair and all persons offering services in disposing of appliances (except for small appliances) must have at least one certified piece of recovery equipment with the evacuation capability as listed in the above paragraph. Before appliances are opened for maintenance, service, and repair, they must be evacuated to the listed levels, except when required otherwise.

b. Service practices. Except for small appliances (see next paragraph for requirements pertaining to small appliances), refrigeration 
equipment must be evacuated before servicing in accordance with the vacuum levels shown in the paragraph above with only certain exceptions. EPA use the term "major repair" to include those repairs involving removal of the compressor, condenser, evaporator, or auxiliary heat exchanger coil. If evacuation of the equipment is not to be performed after the repair is complete, and if the repair is not major, the equipment must be evacuated to at least zero pressure for highor very high-pressure units, or must be pressurized to zero pressure for lowpressure units, in order to minimize contamination of the equipment. If evacuation to the required vacuum level is not achievable due to leaks, or would substantially contaminate the refrigerant being recovered, then the person opening the equipment must isolate leaking from non-leaking components, evacuate non-leaking components to the required levels, and evacuate leaking components to the lowest level that can be attained without substantially contaminating the refrigerant. This level cannot exceed zero pressure.

c. Small appliances. EPA defines small appliances as appliances that are fully manufactured, charged, and hermetically sealed in a factory with 5 pounds or less of refrigerant. Small appliances include refrigerators, room air conditioners, and water coolers. When small appliances are opened for maintenance, service, or repair, service persons must: (1) recover $80 \%$ of the refrigerant in the system, if using recycling and recovery equipment manufactured before November 15, 1993; (2) recover $90 \%$ of the refrigerant for systems having operating compressors, or recover $80 \%$ of the refrigerant for systems having non-operating compressors, if using recycling and recovery equipment made on or before November 15, 1993; or (3) vacuum the system to 13.5 $\mathrm{kPa}$ ( 4 in $\mathrm{Hg}$ ).

d. Reuse of recovered/recycled refrigerant. In instances where ownership of the refrigerant does not change hands, the refrigerant recovered and/or recycled can be returned to the same system or to other systems owned by the same owner. If the refrigerant changes ownership, it must be reclaimed to ARI 700 standard. The latter provision will expire in two years, after the industry develops an off-site recycling standard.

e. Repair of refrigerant leaks. For comfort refrigeration equipment (e.g. chillers, air conditioning units) with refrigerant charges of more than $23 \mathrm{~kg}$ ( 50 lbs), an annual leakage of $15 \%$ or more must be repaired. For commercial refrigeration equipment (e.g. food service freezers), an annual leakage of $35 \%$ or more must be repaired. Owners must repair leaks within 30 days of discovery (or when the leakage should have been discovered). Exceptions are granted if owners, within 30 days, develop a one-year retrofit or retirement plan for the equipment. The plan must be dated and all work under the plan must be completed within one year of plan's date.

f. Technician certification. Effective November 14, 1994, technicians who maintain, service, or repair ODP refrigerant appliances are required to be certified by an EPA-approved certifying organization. The certification program divides technicians into four types: Type I technicians who service small appliances, Type II technicians who service high or very highpressure appliances, Type III technicians who service low-pressure appliances, 
and Universal technicians who service all of the above appliances. Only certified technicians will be able to purchase refrigerants.

g. Other certifications. Owners of businesses engaging in servicing or disposing of refrigeration equipment must certify to an EPA Regional Office that they have acquired recovery or recycling equipment and that they are complying with the applicable requirements. Refrigerant reclaimers must certify to the Recycling Program Manager at EPA headquarters that they are complying with EPA regulations.

h. Equipment disposal. Before refrigeration equipment is dismantled on-site for disposal as in the case of chillers, the refrigerant must be recovered in accordance with EPA requirements for servicing. For equipment that typically enter the waste stream with the charge intact, such as airconditioners and refrigerators, one party in the disposal chain must recover the refrigerant.

i. Record keeping. Owners/operators of appliances containing 50 pounds or more of refrigerant must keep records documenting the dates and types of services, dates and quantities of refrigerants added, and the refrigerants purchased.

3.2.2 Labeling regulations. On January 19, 1993, EPA announced regulations under Section 611 of the Clean Air Act which specify labeling requirements for Class I and Class II substances (PART 82, Subpart E The Labeling of Products Using Ozone-Depleting Substances) (See section 3.2 Clean Air Act and EPA regulations). Labeling regulations are basically aimed at refrigerant and chiller manufacturers, distributors, wholesalers, and retailers. The rule prohibits introduction into interstate commerce of the following products made after May 15, 1993: any container containing class I and class II substances, any product containing class I substances (chillers included), or any product manufactured with class I substances; unless the product bears a warning statement indicating that the product contains or is manufactured with ozonedepleting substance(s). A few instances may touch end users in an ancillary way. Incidental uses of class I refrigerant, such as for leak detection in chillers, are not included in the labeling rule (leak detection application is allowed only for $\mathrm{R}-22$ in a later regulation on recycling, see previous section). The use of ozone-depleting substances for repairs is exempt from labeling requirements. Selling of used products containing class I products (e.g. chillers) also does not require relabeling.

3.2.3 Used oil from refrigeration equipment. EPA regulations concerning used compressor oil are contained in Title 40 CFR Parts 261 (Identification and Listing of Hazardous Waste) and 279 (Standards for the Management of Used Oil). Used oils contaminated with CFCs are not considered hazardous provided that they are not mixed with other waste, that they are subject to CFC recycling or reclamation, and that they are not mixed with used oils from other sources. Even after the majority of CFCs are removed and/or recycled, the presence of CFCs in compressor oil removed from refrigerant units 
may still have halogen levels over $1000 \mathrm{ppm}$. EPA discourages the burning of used oils with significantly elevated levels of halogens in non-industrial furnaces or boilers. If the used oil is destined for burning, it is subject to specification limits for used fuels.

3.2.4 Federal Procurement. On April 1, 1993, EPA published a Notice of Proposed Rulemaking (NPRM) proposing a rule to implement Section 613 of the Clean Air Act which requires all Federal agencies to conform their procurement regulations to the Act. The content of this proposed rule are similar to that in an Executive Order issued later (see next paragraph). It is expected that the final EPA rule will be announced in the near future.

\subsection{Executive order 12843, Procurement Requirements and} Policies for Federal Agencies for ozone-Depleting substances. On April 21, 1993 the President of the United States issued an Executive Order regarding to Government agencies' procurement requirements and policies on ozonedepleting substances. The Executive Order cites requirements of the Clean Air Act Amendments and sets policies and guidelines on procurement and handling of ozone-depleting substances. The order's directives affecting refrigerant use are: minimizing the procurement of products containing Class I substances; amending existing contracts and awarding contracts to be consistent with phaseout schedules of Classes I and II substances; and implementing policies and practices that recognize the effect of phaseout of these substances, such as reducing emissions, recycling refrigerants, ceasing the purchasing of chillers using Class I refrigerants, and labeling products containing Classes I and II refrigerants. The Executive Order specifically directs Federal Agencies to evaluate the present and future uses of ozone-depleting substances, including making assessment of existing and future needs of these substances, altering existing equipment and/or procedures to make use of safe alternatives, specifying the use of safe alternatives that do not require the use of class I substances in new procurement and limiting the use of class II substances consistent with section 612 of the Clean Air Act Amendments. A six-month period is given to Federal agencies to put into effect the changes to minimize the purchase of Class I substances. Also required are reporting requirements directing each Federal agency to submit a report within six months to the Office of Management and Budget regarding the implementation of this order. The six-month deadline is November 21, 1993.

3.4 ASHRAE recommended practices. Recommendations for refrigeration system and refrigerant handling practices to reduce refrigerant emission are contained in ASHRAE Guideline 3 -- Reducing Emission of Fully Halogenated Chlorofluorocarbon (CFC) Refrigerants in Refrigeration and AirConditioning Equipment and Applications. Personnel and property safety issues are contained in ASHRAE Standard 15 - - Safety Code for Mechanical Refrigeration. A brief summary of ASHRAE recommendations are described below.

3.4.1 Safety. In ASHRAE Standard 34 (Designation and Safety Classification of Refrigerants), refrigerants are divided into safety groups 
according to their toxicity and flammability. Toxicity is designated by "A" for lower toxic refrigerants, and "B" for higher toxic refrigerants. Flammability is represented by " 1 " for refrigerants with no flame propagation, "2" for lower flammable refrigerants, and "3" for higher flammable refrigerants. Toxicity and flammability are combined into six groups: A1, A2, A3, B1, B2, and B3. Detailed definitions and test methods for these groups may be found in ASHRAE Standard 34. Most commonly used refrigerants in commercial building cooling (i.e. R-11, 12, 22, 113, 114, and R-134a) are in safety group Al. Refrigerant $R-123$ is in BI which is the higher toxicity group. Toxicity levels of the two newer refrigerants $R-123$ and $R-134 a$ are still being tested and evaluated. ASHRAE Standard 15 also classifies building spaces according to occupancies .. institutional, public assembly, residential, commercial, and industrial .. and to refrigerating system applications rules. The following is a brief discussion of refrigeration safety recommendations involving operation and maintenance.

a. Equipment room monitoring and ventilation. For Group Al refrigerants, equipment rooms must be equipped with an oxygen sensor to warn of oxygen levels below $19.5 \%$ by volume. For all other groups of refrigerants (e.g. B1 which includes R-123), equipment rooms must be equipped with a refrigerant vapor detector which indicates when the vapor level exceeds a certain safety level. Based on toxicity test data released by the Program for Alternative Fluorocarbon Toxicity Testing (PAFT), the refrigerant industry's consensus on the safe allowable exposure limit (AEL) is $10 \mathrm{ppm}$. This level should be the setting of the alarm action. A refrigerant manufacturer has recently revised the recommended AEL to $30 \mathrm{ppm}$ following completion of testing and analysis. The sensors for oxygen or refrigerant vapor must be located in an area in which refrigerant from a leak is likely to concentrate (note that all commonly-used refrigerants except ammonia are heavier than air). The alarms of the sensing system shall automatically trigger mechanical ventilation which will discharge the air to the outdoors, in such a manner as not to cause danger. Periodic tests of the detectors, alarms, and mechanical ventilation systems shall be performed. The purpose of the alarm-activated ventilation is to purge refrigerant in case of massive leaks. The required amount of ventilation in these cases is based on the mass of refrigerant in the largest refrigeration system in the space. The normal required ventilation rate is lower and is based on the floor area or the number of occupants $\left(2.54 \mathrm{~L} / \mathrm{m}^{2}\left(0.5 \mathrm{cfm} / \mathrm{ft}^{2}\right)\right.$ or $9.44 \mathrm{l} / \mathrm{s}$ per person (20 cfm/person)). Natural ventilation is allowed when the refrigeration system is located outdoors more than $6.1 \mathrm{~m}$ (20 ft) away from any building opening and is enclosed by a penthouse. Equations for ventilation rate calculations are given in the standard.

Although the standard requires oxygen sensors to be used for Al refrigerants and only one sensor or detector to be installed in an equipment room, it is more effective to use refrigerant vapor detectors for all refrigerants or to use multiple sensors in one room.

b. Equipment room doors. Refrigerating equipment rooms shall have tight fitting doors which open outward. Equipment room doors which open to the other parts of the building must be self closing. No other openings are 
allowed that may cause refrigerant to escape to other parts of the building.

C. Equipment room access. Access to refrigerating equipment rooms is restricted to authorized personnel only. Signs to reflect this restriction should be posted.

d. Open flame. No open flame heating equipment is allowed in the refrigeration equipment room when the room air is used as combustion air.

e. Pressure relief pipes. Pipes from pressure-relief devices (including purge systems) of the refrigeration equipment shall discharge to the atmosphere not less than $4.57 \mathrm{~m}$ ( $15 \mathrm{ft}$ ) above the adjoining ground level and not less than $6.1 \mathrm{~m}$ (20 ft) from any window, ventilation opening, or exit in any building.

f. Refrigerant storing. Refrigerant withdrawn from refrigeration systems shall be transferred to approved containers only. Refrigerant stored in an equipment room shall not be more than $150 \mathrm{~kg}$ ( 330 lbs) in addition to the charge in the system and the refrigerant stored in a permanently attached receiver.

g. Stop valves. All stop valves connecting refrigerantcontaining parts to atmosphere during shipping, testing, operating, servicing, or standby conditions shall be capped, plugged, blanked, or locked closed when not in use.

h. Instructions. Schematic drawings of system operation shall be posted in the equipment room. Emergency procedures including instructions for shutting down the system and the name, address, and day and night telephone numbers for obtaining service shall be posted outside the equipment room immediately adjacent to each door.

i. Pressure gauges. Calibrate pressure gauges prior to test and after occasions of unusually high pressure.

j. Breathing apparatus. Provide at least one approved selfcontained breathing apparatus outside of, but close to, the equipment room door.

3.4.2 Reduction of refrigerant emission. ASHRAE Guideline 3 (Reducing Emission of Fully Halogenated Chlorofluorocarbon (CFC) Refrigerants in Refrigeration and Air-Conditioning Equipment and Applications) covers chiller system design, manufacture, installation, servicing, operating, and maintenance. It also discusses topics in refrigerant recovery, reuse, and disposal; personnel training; and handling and storage of refrigerants. The Guideline is a generic, detailed, and fairly complete document on reducing refrigerant emission of refrigeration equipment. Although this document is not a substitute for manufacturers' operating and maintenance manuals for specific chillers, this Guideline or a modified version of it with similar recommendations should be made available to all GSA building maintenance personnel as a general reference. The 
following paragraphs briefly list the topics discussed in the standard.

a. Equipment installation and service sections describe piping fabrication and installation; equipment leak testing, evacuation, and charging; routine servicing of system; cleaning of system after mechanical failures, refrigerant contamination, and motor burnouts.

b. Systems operation and maintenance sections include inspections to compressors, heat exchangers, and purge units. Also discussed is water filtration and treatment.

c. Listed recommended monitoring and logging points for centrifugal and large positive displacement refrigeration systems. Important parameter data, their repercussions, and possible faults are discussed.

pressure chillers.

d. Describes maintenance steps to reduce refrigerant leaks from low

e. Discusses refrigerant recovery, reuse, disposal, and storage. Recommendations include installing new filter-dryer elements before returning recycled refrigerant to the system; analyzing refrigerants for contaminants and taking appropriate remedial procedures or processes before reuse when refrigerants are taken out of equipment because of mechanical failure, refrigerant contamination, or motor burnout; Storing mixtures of refrigerant and inert gas that are used for leak testing for future reuse as leak-test gas; filling refrigerant containers not to exceed $80 \%$ of liquid fill at $21{ }^{\circ} \mathrm{C}\left(70{ }^{\circ} \mathrm{F}\right.$ ); and using containers constructed to meet DOT requirements, including properly set relief valves and valve guards. There are numerous other recommendations. However, as discussed previously, recent EPA regulations mandate generally more stringent measures for these topics. Adaptation of the Guideline recommendations should be viewed together with the new regulations.

f. Provides an information list for subjects suggested to be included in training personnel.

3.5 Assessment of current GSA refrigerant handling practices. A GSA Refrigerant Management Plan was issued in September 1992. The plan provides guidance to implement GSA's policy to "economically select, efficiently use, recover, recycle, and reclaim the refrigerants and to safely handle, store, and dispose of them." There are three principle guidelines for operation, maintenance, repair and replacement of chillers: a) taking action to reduce the loss of ozone-depletion refrigerants for existing chillers; b) conducting lifecycle cost studies to determine conversion of chillers from CFC to HCFC to HFC when major repairs are required; and c) procuring replacement or new chillers with HCFC or HFC refrigerants only. Under this Plan, GSA has designated a facility refrigerant manager in each region as the coordinator. This manager coordinates across the functions of design, construction, operation, maintenance, and safety issues on all refrigerant related programs. The refrigerant 
Management Plan lists six major areas for concentrated management efforts: a) chiller inventory; b) operations and maintenance practices; c) refrigerant containment; d) safety and personnel; e) refrigerant recovery, recycling, and reclamation; and $f$ ) chiller repair or new chiller procurement. Under each area, the Plan highlights essential aspects for consideration. However, implementation details are not elaborated. The subsequent discussion follows the same major areas as listed in the GSA Plan:

3.5.1 Chiller inventory. The Refrigerant Management Plan calls for creating and maintaining a computer database on chillers, including centrifugal, screw, reciprocating, and absorption units. Contained in the database is information on GSA regions, cities located, building numbers, chiller manufacturers, model numbers, serial numbers, compressor types, chiller capacities, year installed, refrigerant types when designed, current refrigerant types, repair or replacement dates, and comments. A sample printout is shown in Appendix A. The inventory list is intended to be used to provide management options on chiller and refrigerant requirements, to assess potential impact of regulations on refrigerant related issues, as well as to supply information for other management decisions, such as for budgetary planning. Information on refrigerant inventory are not currently collected. Because of the complex nature of GSA facilities, an inventory database that includes refrigerant inventory and other key information is essential in refrigerant management and planning. NIST also recommends that compressor motor enclosing arrangement (hermetic or open) be added to the database. Because of the limited supply of certain refrigerants in the future, refrigerant inventory data will be increasingly important in chiller maintenance and refrigerant management. The amount of refrigerant charge in each chiller, the amount of refrigerant per year that was added to each chiller, and the kind and the amount of refrigerants in storage in each administrative area (e.g. buildings under the same maintenance group and/or in each GSA Regions) should be collected. If no detailed record was kept, the amount of added refrigerant per year should be estimated.

It would also be useful to have major repair records, such as the time and nature of overhaul performed, general condition of the chiller, included in the database. The last item may require judgmental evaluations by the maintenance personnel of the buildings and may be categorized into groups, such as good, fair, and poor. However, most, if not all, of these data should be available from maintenance records. The inventory data should be updated periodically (e.g. semi-annually). The computer program for the sorting and display of data should be designed to enable regional refrigerant managers or GSA central office personnel to pick out the selected data for certain purposes and intended analysis. With updated inventory data, the ability of regional refrigerant managers and GSA central office management will be enhanced greatly in analyzing future refrigerant procurement planning and in making decisions of chiller conversions and replacements. Chiller conversions and replacements will be discussed further later.

3.5.2 Operations and maintenance practices. GSA Refrigerant Management Plan lists several essential aspects of operation and 
maintenance practices: general operations and equipment performance of chillers, preventive maintenance of chillers, record maintenance of chiller operating logs and refrigerant related data, personnel training and education, and contract services pertaining to refrigerant related items. It cites general references discussed earlier in this report: Title 40 of CFR, Part 82 (Protection of Stratosphere Ozone) and American Society of Heating, Air Conditioning, and Refrigerating Engineers (ASHRAE) Guideline 3 (Reducing Emissions of Fully Halogenated Chlorofuorocarbon Refrigerants in Refrigeration and Air Conditioning Equipment and Applications). It also refers to manufacturer's manuals and GSA guides for details of practices. NIST recommends that generic practices of refrigerant handling (not related to a specific chiller), chiller operating and maintenance procedures, and details of personnel training and education be included in the GSA Building Maintenance Management Handbook and/or in other relevant manuals to accommodate upgrading of practices, to promote uniform implementation among regions, and to facilitate easy use by operating and maintenance personnel.

3.5.3 Refrigerant containment. Included in this major area are "minor" modifications to chillers which will reduce the loss of CFC and HCFC refrigerants during normal operations, maintenance, and service of HVAC equipment. Included are bullet items related to purge, refrigerant leaks, oil service, chiller monitoring and controls, chiller fittings and accessories, and other related items. Detailed discussion of refrigerant leak detection and appropriate references could be added in the Building Maintenance Management Handbook. Some examples of relevant practices which may reduce refrigerant losses are:

refrigerant leakage.

a. Good motor-compressor alignment is important for reducing

b. Machine vibration causes leaks. Attention to component balancing, bearing and gear-set alignment, piping support, piping vibration elimination, and machine mounting can all help to reduce chiller vibration.

c. When external seals are used as in the case of open motors, maintaining oil at seal faces will reduce leaks. For prolonged shutdown, maintenance should include procedures to periodically oil seal faces. Shutdown and startup procedures should be designed to assure that seals are kept oiled.

d. Conduct frequent inspection and leak detection. Oil leaks are indications of possible refrigerant leaks.

e. The procedures for assessing purge unit replacement for low pressure centrifugal chillers should be added and expanded. The pressure in the low pressure segment of the refrigerant circuits of low pressure chillers is below atmospheric pressure, and consequently air and associated moisture leak into the refrigerant systems of these chillers. In order to get rid of the air and moisture, purge units are universally installed on low pressure chillers. Periodically, the purge units are turned on manually or automatically for a short 
amount of time. The noncondensible gases in the condensers mixed with refrigerant is pumped through the purge units. Part of the refrigerant in the purge units is recovered and pumped back to the chillers. However, part of the refrigerant is expelled with the noncondensibles to the atmosphere. For low pressure chillers built before two or three years ago, the refrigerant loss through purging is quite large. Some estimates put the loss of some purge units as high as over $80 \%$ of the total purged mass. (ASHRAE, 1990) New high efficiency purge units can reduce refrigerant loss to less than $1 \%$ of the total purged mass. It is evident that replacing inefficient purge units should be a high priority item for reducing refrigerant emission. However, the decision of whether to replace an existing purge unit of a chiller should not be solely based on the records of refrigerant consumption rate and the purge unit operating time. A thorough inspection of the chiller for possible large leaks, such as leaks caused by bad seals, and a review of purge unit relief valve setting against specifications should be conducted. Replacing purge units should also be considered together with chiller conversion and replacement which will be discussed later.

3.5.4 Safety of personnel. This major area pertains to the protection of operating personnel and property. The Plan furnishes a list of essential safety items, such as refrigerant sensors and alarms for chiller rooms, automatic ventilation and refrigerant evacuation systems, refrigerant relief, safety data sheet documentation, safe handling procedures for refrigerants, and other general safety related issues. Safety related references are also given: Title 29 CFR Parts 1910 and 1926 (Occupational Safety and Administration's Standards), ASHRAE Standard 15 (Safety Code for Mechanical Refrigeration), and ASHRAE Standard 34 (Number Designation and Safety Classification of Refrigerants). For the same reason as stated in Operations and Maintenance Practices paragraph above, NIST recommends that a more detailed discussion of the listed essential aspects be added and/or expanded in the Building Maintenance Management Handbook or other relevant manuals.

3.5.5 Refrigerant recovery, recycling, and reclamation. This area of the GSA Plan references ARI Standards 700 (Specifications for Fluorocarbon Refrigerants) and 740 (Performance of Refrigerant Recovery, Recycling, and/or Reclaim Equipment), and the proposed EPA ruling of Title 40 CFR Part 82 Subpart $F$ (Recycling and Emissions Reduction). The last referenced document was revised and has became regulation since the issuance of the GSA Plan, and is discussed in a previous section in this report. Since the final EPA regulations on refrigerant recycling is very new, this area of the Plan should be reviewed to incorporate EPA's new regulations. Expanded discussion should also be given for the reasons stated previously.

3.5.6 Chiller repair or procurement. This major area relates to the decisions of major repair of existing chillers, the acquisition of new chillers, and the conversion of existing chillers to the use of alternative refrigerants. The essential aspects for consideration for such actions are listed in the $\mathrm{Plan}$. The $\mathrm{Plan}$ requires life-cycle cost analyses for new chiller procurement, existing chiller conversion and major repairs of 
existing chillers.

GSA initiated a no-CFC policy on procuring new chillers in February 1992 when the phaseout of CFC was accelerated from the year 2000 to the end of 1995 .

Approximately two-third of GSA's CFC chillers have reached their expected useful life. Their operation, maintenance, and repair costs are increasing. GSA has a plan to replace older chillers, typically 25 years or older, within the next three to five years. This accelerated replacement is planned as a design-build prospectus.

3.6 Refrigerant handling recommendations. The GSA Refrigerant Management Plan covers quite well all aspects of current concerns of ozonedepletion refrigerant issues. However, in its present form, the Plan basically consists of bullet items and brief guidelines. Details of execution to achieve the objectives are mostly left to refrigerant managers and the maintenance personnel in regional offices. Indeed, all GSA regions have plans at various stages to retrofit or replace CFC refrigerants to transitional (R-123 for low pressure chillers) or non-ODP refrigerant (R-134a for high pressure chillers). However, the GSA Plan's effect would be further enhanced by the expansion of the contents of the Plan's scope, either in the Plan itself or in other operating and maintenance documents, to include procedures, criteria, and other specific information to assist the implementation by refrigerant managers and the maintenance personnel.

Due to the imminent production phaseout of CFCs, two industry-wide problems may appear in the near future: the possible rush of chiller owners to convert their CFC chillers to use non-CFC refrigerants, thus straining the abilities of manufacturers/contractors to perform chiller conversions; and the anticipated shortage and higher cost of CFCs. EPA estimates that there are over 80,000 centrifugal chillers using CFCs or HCFCs in this country. A recent survey conducted by ARI indicates that only about 13,000 are expected to be converted or replaced before the end of 1995. Although GSA has a plan to replace older chillers in the next three to five years (see section 3.5.6), in order to avoid being trapped in this anticipated conversion/replacement squeeze, it is important for GSA to expedite implemention of the plan as quickly as possible.

Until now, refrigerant availability has been a factor that has not been considered in the decision to acquire chillers. The life-cycle cost method (as required in GSA Refrigerant Management Plan) is the only required criteria for major repairs, conversions, and replacements. If a shortage of certain ODP refrigerants develops in the future, refrigerant availability may play a significant role. Decisions of chiller conversions and replacements must consider refrigerant inventory on hand and projected future needs. In addition to comparing repair/conversion/replacement costs against future operating and maintenance costs (including examining chiller conditions, repair records, chiller age, operating efficiency, makeup refrigerant cost, etc.), each GSA region, as a unit, should also develop a chiller conversion/replacement list for 
each ODP refrigerant. This list should contain the amount of current and future refrigerant needs and should rank all chillers in the region in the desired conversion/replacement order. A determination of the dividing line between retrofit (or do nothing for new chillers) and conversion/replacement then can be made, based on the available budget and refrigerant. The projected future refrigerant needs in the region depend on the current refrigerant inventory, both in chillers and in storage, and on the number of chillers to be converted. A spread sheet computer program is suitable for this exercise. Chiller efficiencies should be available from recorded historical data. Note that direct conversion without certain changes of the machine components may result in capacity loss and efficiency decrease. Therefore, chiller capacity after intended conversion should also be checked and compared with building load. Historical building load of the past few years should be used for this comparison. Generally, older chillers in poor conditions, having low operating efficiencies, and having scheduled major repairs should be on the high priority end of the conversion/replacement list.

GSA's chiller inventory data (as of September, 1992) indicates that there are over 1700 pieces of refrigeration equipment over approximately $90 \mathrm{~kW}$ (25 coolington) capacity. The total number of chillers using CFCs and their azeotropes ( $R$ $11,-12,-113,-114$, and -500 ) with capacities at or over $350 \mathrm{~kW}$ (100 cooling tons) is 684. The majority of these-large capacity chillers are of the centrifugal type. Of these 684 chillers, approximate $74 \%$ use low pressure refrigerant R-11 or -113; approximately $20 \%$ use high pressure refrigerant R-12, 114 , or -500 ; and only about $6 \%$ use alternate refrigerants $\mathrm{R}-123$ or $-134 \mathrm{a}$. It is clear from these statistics that considerable efforts should be exerted to examine existing chillers that use ODP refrigerants, especially low pressure chillers. An overall equipment modification procedure and strategy, together with a refrigerant management plan, should be devised. These can best be administered regionally, since even the smallest GSA regions have at least 30 chillers in capacities at or over $350 \mathrm{~kW}$ ( 100 tons) ( 32 in Region 8 and 31 in Region 10 with total cooling capacities, including all chillers, of $32,800 \mathrm{~kW}$ $(9,326$ cooling tons) and $35,670 \mathrm{~kW}$ ( 10,143 cooling tons), respectively). All refrigeration machine using the same CFC should be included in the same retrofit/conversion/replacement plan. Two tiers of tests should be performed: the first test to determine the merit of retrofit, conversion, or replacement; and the second test to learn if the refrigerant will be available for the planned period. The first test should follow the GSA standard procedure for major repairs and replacement which requires a life-cost analysis. The second test is to calculate the number of years the refrigerant will be adequately provided. A decision path is shown on the next page. 


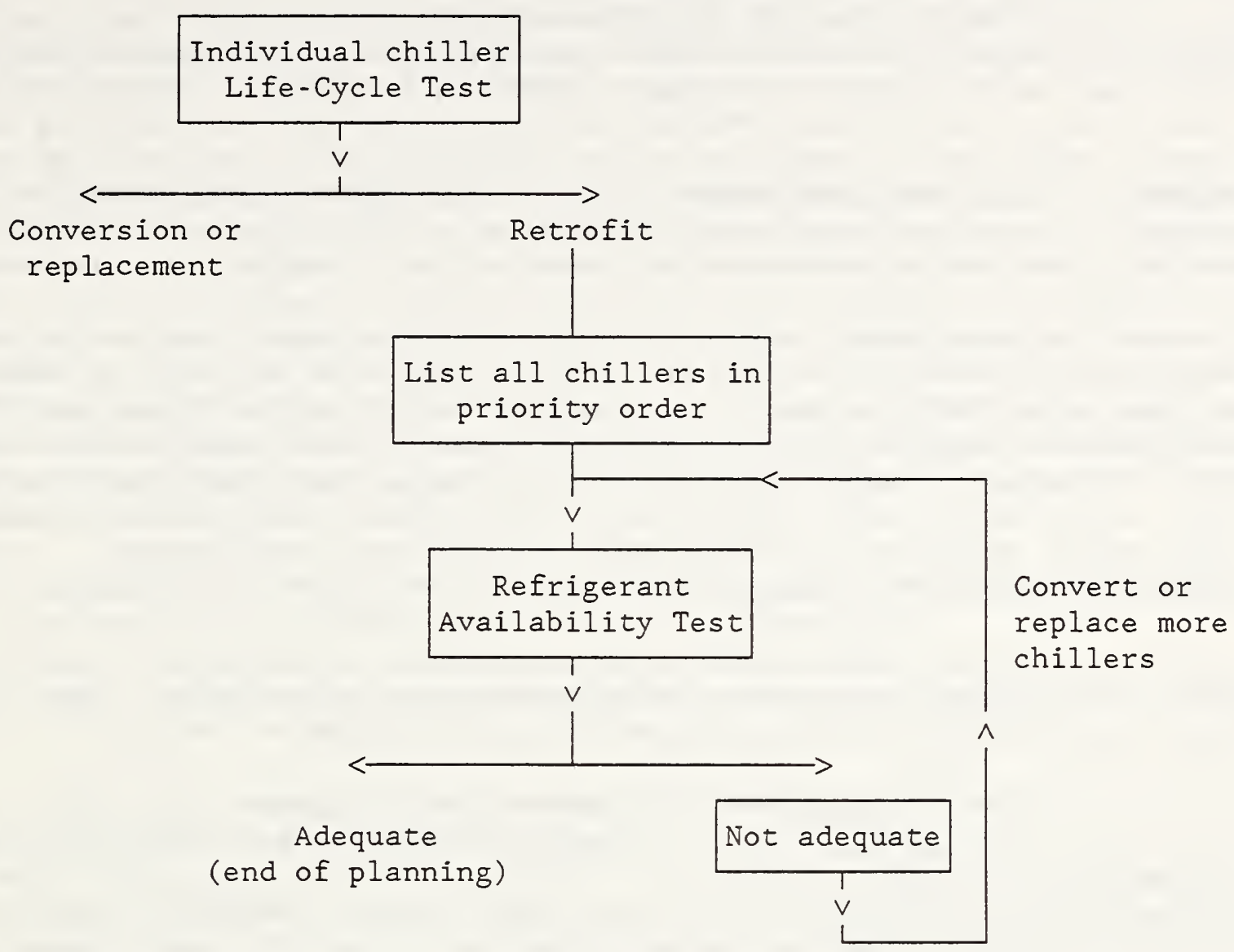

The retrofit, conversion, and replacement options are further discussed below. However, none of these options should be considered in isolation. Rather, each option should be viewed as a piece of the entire plan.

3.6.1 Chiller retrofit. The basic purpose of retrofitting existing chillers is to conserve existing refrigerants. Retrofit of centrifugal chillers mainly includes providing high-efficiency purge units for low pressure chillers. This is discussed in detail earlier in this report. Also needed are measures to prevent refrigerant leaks in larger scales than ordinary maintenance procedures. These include replacing all seals and gaskets in problematic chillers and adding refrigerant holding storages, isolation valves, and heating devices (for low pressure chillers only). The purpose of having storages and isolation valves is to accommodate isolated refrigerant storages during off seasons and major repairs for chillers that do not have leak-tight storages. For chillers that do not have pump-down capabilities, pump-down units may need to be added. The purpose of having heating devices in low pressure chillers is to keep a slightly positive pressure in the systems to prevent air leakage. Any fully isolated refrigerant storage must be protected with pressure relief valves as 
required in ASHRAE Standard 15.

3.6.2 Chiller conversion. The current practice in centrifugal chiller conversion is to use R-123 in low pressure chillers and to use R-134a in high pressure chillers. Depending on the refrigerant used and on the type and conditions of the chiller, chiller conversion may involve replacing seals and gaskets, replacing or rewinding motors, changing gears, replacing or modifying compressor impellers, replacing oil and refrigerant, and modifying control systems. The costs vary widely depending on the scope of change. Chiller manufacturers should definitely be consulted for specific chiller conversions.

As mentioned previously, HCFCs are scheduled to be phased out by the year 2030 . The question of whether to convert existing chillers to R-123, to purchase new chillers using R-123 or R-22, or to replace chillers directly to non-ODP R-134a should not be a major concern, because 36 years, from the present to the year 2030 (and perhaps longer considering recycling and reclaiming refrigerants), is long enough for the life cycle of a chiller. Additionally, intense research is still being conducted to find other alternative refrigerants. Definitive conclusions, now, of refrigerant outcome in the future can hardly be assured.

3.6.3 New chiller procurement. Following the Executive Order 12843, no chillers using CFC as refrigerants can be purchased. This policy is being practiced by GSA as mentioned in section 3.5.6.

3.6.4 Chiller room survey and update. All machinery rooms containing refrigeration machines should be inspected for satisfying the safety requirements of ASHRAE Standard 15. Focal points are refrigerant leak warning and ventilation systems, refrigerant relief piping conformity, machinery room access door rules, and other safety requirements as discussed in section 4.

3.6.5 Education and certification program for operation and maintenance personnel. In order to fulfill the EPA requirement of certification of personnel engaged in maintaining, servicing, repairing, and disposing of refrigeration equipment, regional offices should have their operating and maintenance personnel certified with the appropriate types in accordance to their work assignment before the November 14, 1994 deadline. On September 30, 1993, EPA has approved GSA as a certifier for technicians. Classes conducted by in-house personnel or outside contractors to educate service personnel on general ODP knowledge and specific certification material have been initiated and should be continued.

3.6.6 Procurement of recovery and recycling equipment. Each building or building group should have at least one piece of recovery and recycling equipment that meets the EPA required evacuation level and is certified by an EPA approved testing laboratory.

3.6.7 Refrigerant record keeping program. Each operating and maintenance unit (building or building group) should keep a refrigerant account log which should include date, amount purchased, amount dispensed, where 
disposed (equipment identification or organization disposed to), and the current inventory amount. This information together with the estimated amount of refrigerant contained in the equipment should be sent periodically to the Refrigerant Manager for regional planning. Records for each kind of refrigerant used in the same maintenance unit should be kept separately.

3.7 Assessment of GSA "CFC SPECIFICATION". The undated specification documents NIST received from GSA consist of two parts. The first part is a complete four-page specification. The second part is associated with a certain specific project. Both specifications are intended to be appended to maintenance contracts to incorporate ODP refrigerant requirements. Copies of these specifications are attached in Appendix B. These specifications are quite complete and specific for their intended requirements. However, they were developed before many of the recent regulations were published. Therefore, a general revision should be conducted to incorporate these new rules. NIST recommends the following revisions:

a. Reclaimed refrigerants should meet the standard of purity as specified in ARI Standard 700, not ASHRAE purity levels as specified.

b. Add certification requirements for contract personnel involved in servicing refrigerant equipment.

c. Add requirement that the contractor must possess recovery/recycling equipment with EPA approved certification.

d. Clarify disposal of used refrigerants, including refrigerants recovered from equipment that itself is to be disposed of. Depending on the quantity of the refrigerant and the method of disposing (e.g the contractor may have possession of the small amount of refrigerant from a window unit; the contractor may give monetary credit to the Government for refrigerant recovered from a large chiller; or the contractor may provide service to have the refrigerant reclaimed for the Government.)

e. Add requirement of disposing of used oil. Used oil from refrigeration equipment should not be mixed with used oil from other sources.

f. Date and amount of refrigerants purchased, reclaimed, stored, used, and disposed should all be recorded.

g. Maintaining refrigerant record for each building only is inadequate. Records of the amount used in each piece of equipment as well as for each building should be kept.

h. Correct the words "reclaimed" and "recovered". Their use are sometimes intermixed in the text. 


\section{SUMMARY OF RECOMMENDATIONS.}

\subsection{Large centrifugal chiller maintenance practices.}

1. The current maintenance practice of having GSA central office issuing PM guides as minimum requirements, and allowing regional offices and building maintenance personnel flexibility in meeting these requirements, is a sensible policy.

2. In addition to documenting suction and discharge purge pressures, record purge unit accumulated run time and purged moisture volume on the Refrigeration Operating Record form (Form 480) or other suitable forms.

3. Perform a general survey of lighting conditions in mechanical rooms to insure lighting adequacy for reading and observing chiller operating conditions. Pay attention to light intensity, shadow, and glaring.

4. Add standard procedures for chiller leak testing to include general testing (applying pressure or vacuum for at least 24 hours) and leak location testing (using soapy solution, halogen detector, or electronic detector). This may be accomplished by revising PM guide R-5 (Refrigeration Machine, Centrifugal) or establishing a new PM guide.

5. Add standard procedures for high and low pressure chiller evacuation and charging. This may be accomplished by revising $P M$ guide $R-5$ (Refrigeration Machine, Centrifugal) or establishing a new PM guide. Recommended evacuation levels are discussed in section 2.2.3.

6. Add vibration test and analysis as a standard technique for routine testing of motor and rotor balance, bearing and gear alignment, and bearing and gear wear. Use accelerometer type pickups for gears and bearings (high frequency), and piezoelectric velocity pickups for compressor motors, rotors, and bearings (low frequency). Users must be trained to perform vibration tests and analysis. See item 17. below for pilot project discussion. Description of vibration analysis is in section 2.2.4.

7. Add infrared thermal technique to test thermal insulation integrity, "hot spots" in compressor motors and starter, and electrical panels. Thermography type technique is not recommended. Use infrared thermometry units with adjustable emissivity feature for better readings. This technique is not limited in chiller maintenance. A new PM guide may be established. Revise PM guides R-5, R-6 (Refrigeration Controls, Central System), M-10 (Motor Controller Unit, 2200 volts and above, and $200 \mathrm{HP}$ and above), and E-28 (Motor Starters, 100 HP and up) to reflect this requirement. Discussion of infrared thermal technique is in section 2.2.5.

8. Continue the current GSA practice of using eddy current technique 
in condenser and evaporator tube examination. Add a requirement in PM guide R-13 (Non-Destructive Chiller Tube Analysis) that the replaced tubes as results of eddy current testing should be examined and the causes of tube defects reported. This is a different requirement from the eddy current test report requirement. Discussion of eddy current examination is in section 2.2.6.

9. Use oil analysis as a routine non-destructive testing for chillers. Oil should be analyzed periodically for moisture content, acidity, and contents of metals. Metals should include aluminum, chromium, copper, iron, lead, tin, silicon, and zinc. Revise PM guide R-5 to use oil analysis to determine more than bearing conditions (Check Point 5). Discussion of oil analysis is in section 2.2.7.

10. Review the frequency of maintenance of large motor starters to reconcile the difference between those specified on PM guide E-28 (Motor Starters, 100 Horsepower and Up) and other chiller related PM guides. An annual maintenance of chiller starter is appropriate.

11. Add warnings in "Special Instructions" or in "Check Points" on PM guides M-3 (Motors) and/or R-5 (Refrigeration Machine, Centrifugal) not to apply higher voltage to hermetic motors than the motor nameplate rated voltage, nor to apply over 50 volts to motor windings when they are under vacuum.

12. Review Special Instruction 2 of $P M$ guide $R-5$. PM guide R-6 (Refrigeration Controls, Central System) should also be referenced.

13. Strengthen requirement of instrument calibration. Simple instruments such as pressure gauges and thermometers may be calibrated by inhouse personnel. Add calibration principles and guidelines in the Building Maintenance Management Handbook. Calibration of other instruments should be contracted to chiller manufacturers or calibration laboratories. An instrument calibration frequency schedule should be developed. Calibration of instruments are discussed in section 2.3 .

14. After chillers have had major overhauls, perform NDT to record base conditions of the chillers. Most of the NDT techniques (eddy current testing, vibration analysis, electrical insulation testing, and oil analysis) discussed in this study should be used to establish base conditions. This is essential in applying predictive maintenance on chillers.

15. Institute trending technique to track chiller conditions. This technique is strongly recommended in GSA chiller maintenance. With the base chiller data obtained in item 14 above and subsequently collected periodic test data, historical changes of the tested parameters may be plotted to predict machine conditions. In addition to the data stated in item 14, low pressure chiller purge unit running time, the amount of purged water, and the amount of refrigerant added per unit time should all be plotted against time to map chiller conditions. Develop plotting forms with coordinates of time (compressor running time or calendar time) vs. test parameters. 
16. Consider using oil analysis data as criteria for oil change or using these data to supplement fixed oil change schedules (PM guide R-5).

17. Establish pilot groups to explore NDT techniques in chiller maintenance. In addition to performing actual maintenance, these groups will also collect data and analyze results to determine the cost effectiveness of these techniques and the appropriateness of applying these tests nationwide.

\subsection{Refrigerant management practices.}

1. New refrigerant technology and Government regulations are still evolving. GSA maintenance personnel should be attentive to new developments. GSA Central or Regional offices (involving at least Regional Refrigerant Managers) should have scheduled (preferably yearly) refrigerant handling reviews of requirements of refrigerant related laws and EPA regulations, as well as recommendations by professional organizations (mainly ASHRAE and ARI). Current documents relevant to chillers are listed in the reference section. Some of these documents should be referenced in maintenance documents (PM guides) to assist users in locating specific concerns.

2. Beginning July 1,1992 , the law prohibits individuals from knowingly venting ozone-depleting refrigerants into the atmosphere while maintaining, servicing, repairing, or disposing of refrigerant related equipment. Certain exceptions are given. This law is contained in the Clean Air Act and is reiterated in EPA regulations for section 608 of the Act (Recycling and Emission Reduction). This section should be referenced in PM guide R-5. Discussion of EPA recycling rules are in section 3.2.1.

3. Each building or building group should procure at least one piece of refrigerant recovery and recycling equipment. These equipment are certified by EPA in accordance to the year they are manufactured and their targeted use. The required vacuum level are grouped by the kind of refrigerant, equipment pressure level, and the amount of refrigerant charge. Add a Check Point in PM guide R-5 to evacuate chillers to the EPA required levels before they are opened for service.

4. Add a Check Point in PM guide R-5 that service personnel should use valves to isolate leaking components from non-leaking components during service and repairs.

5. Add a Check Point in PM guide R-5 that if evacuation of the chillers is not planned after repairs, chiller pressure must be maintained at about atmospheric pressure to avoid refrigerant contamination.

6. Add in the Building Maintenance Management Handbook that only reclaimed refrigerants meeting specifications of ARI 700 standard shall be purchased and used. 
7 Add in the Building Maintenance Management Handbook or desk guide a requirement to inspect centrifugal chillers for refrigerant leaks when more than normal leakage is suspected. Be aware of the requirement that if the chiller leaks refrigerant $15 \%$ or more annually, it must be repaired within 30 days of the discovery, unless one-year retrofit or retirement plans are developed within 30 days.

8. Proceed to have maintenance personnel, who are involved in servicing, maintenance, repair, or disposal of refrigeration equipment, certified as appropriate.

9. Add in the Building maintenance Management Handbook that before chillers are disposed, the refrigerant must be recovered in accordance with EPA vacuum level requirements.

10. Continue the practice of keeping refrigerant account logs in each building or building group to record date, amount purchased, amount dispensed, where dispensed, and the current inventory amount.

11. Follow directives of Executive Order 12843. A brief discussion is given in section 3.3 of this report.

12. Add motor enclosing arrangement, the amount of refrigerant charge, the amount of supplemental charge per year, major repairs, and the general conditions of chiller (good, fair, and poor) in the chiller inventory database. The amount of refrigerant in storage should also be included in the inventory database.

13. Add generic refrigerant handling practices, chiller operating and maintenance procedures, and details of personnel training requirements in Building Maintenance Management Handbook or other manuals.

14. Alert maintenance personnel that refrigerant loss is directly related to chiller maintenance conditions. In PM guide R-5 stress that motorcompressor misalignment, severe machine vibration, etc., may cause excessive refrigerant loss. Frequent leak inspection and detection, and techniques to maintain refrigerant seals should also be noted. Details are discussed in section 3.5 .3 .

15. Add assessment procedures for inefficient purge unit replacement for low pressure chillers in conjunction with chiller conversion/replacement. Discussion is given in section 3.5.3.

16. Expand discussion of safety aspects of chillers in maintenance instructions. Recommendations are given in ASHRAE Standard 15 and are briefly discussed in section 3.4.1 of this report. Main aspects are:

16a. Provide oxygen or refrigerant vapor (preferred) sensors and alarms in chiller rooms to alert personnel of high refrigerant leaks and to activate ventilation fans. 
16b. Chiller room doors must open outward. Provide self-closing doors when the chiller room door opens to other parts of a building.

16c. Provide signs to restrict unauthorized persons from entering chiller rooms.

16d. Prohibit placing open flame heating equipment in chiller rooms.

16e. Chiller pressure relief pipes must be discharged to the outside of building following recommendations contained in ASHRAE Standard 15.

16f. Use approved containers for refrigerant storage and store no more than $150 \mathrm{~kg}$ (330 lbs) of refrigerant in chiller rooms.

16g. Cap, plug, or use other means on all refrigerant stop valves which open to atmosphere, when they are not in use.

16h. Post chiller operating procedures, emergency procedures, and other recommended information as required.

16i. Recalibrate pressure gauges after they are subjected to overpressure conditions.

16j. Provide approved self-contained breathing apparatus for each chiller room.

17. Conduct periodic chiller room surveys to assure compliance of safety recommendations as listed above.

18. Add in PM guide $R-5$ that used oils from chillers must not be used as fuel in boilers and must not be mixed with other waste or used oil from other sources.

19. Plan and execute centrifugal chiller retrofit/conversion/replacement schemes as rapidity as possible in all GSA regions. Criteria for action should be based on refrigerant type, chiller age, chiller conditions, anticipated refrigerant requirement, anticipated future refrigerant consumption and recovery, and current storage capacity. All these data are (and should be) included in chiller inventory database. Detailed discussion is given in sections $3.6,3.6 .1$, and 3.6.2.

20. Review comments on GSA "CFC SPECIFICATION" are given in section 3.7. Revise as indicated.

21. Add sample specification, similar to GSA "CFC Specification" in item 20 above, in the Building Maintenance Management Handbook or other related maintenance documents as guide specifications to promote uniform application among regions. 


\section{REFERENCES •}

ARI Standard 700, "Specifications for Fluorocarbon Refrigerants," AirConditioning and Refrigeration Institute, Arlington, VA.

ASHRAE Guideline 3, "Reducing Emission of Fully Halogenated Chlorofluorocarbon (CFC) Refrigerants in Refrigeration and Air-Conditioning Equipment and Applications," American Society of Heating, Refrigerating and Air-Conditioning Engineers, Inc., Atlanta, GA.

ASHRAE Standard 15, "Safety Code for Mechanical Refrigeration," American Society of Heating, Refrigerating and Air-Conditioning Engineers, Inc., Atlanta, GA.

ASHRAE Standard 34, "Number Designation and Safety Classification of Refrigerants," American Society of Heating, Refrigerating and Air-Conditioning Engineers, Inc., Atlanta, GA.

Executive Order 12843, April 21, 1993, "Procurement Requirements and Policies for Federal Agencies for Ozone-Depleting Substances." Federal Register, vol. 58, no. $77,21881-21883$.

United Nations Environmental Programme/World Meteorological (UNEP/WMO), September 5, 1989, "Scientific Assessment of Stratospheric Ozone: 1989."

U.S. Environmental Protection Agency, July 30, 1992, "Protection of Stratospheric Ozone; Final Rule," Federal Register, vol. 57, no. 147, 33754-33798.

U.S. Environmental Protection Agency, September 10, 1992, "Hazardous Waste Management System; Identification and Listing of Hazardous Waste; Recycled Used Oil Management Standards; Final Rule," Federal Register, vol. 57, no. 176, 41566 41626.

U.S. Environmental Protection Agency, February 11, 1993, "Protection of Stratospheric Ozone; Labeling; Final Rule," Federal Register, vol. 58, no. 27, $8136-8169$.

U.S. Environmental Protection Agency, April 12, 1993, "Protection of Stratospheric Ozone; Notice of Proposed Rulemaking (NPRM)," Federal Register, vol. 58, no. 68, 19080-19087.

U.S. Environmental Protection Agency, May 14, 1993, "Protection of Stratospheric Ozone; Refrigerant Recycling; Final Rule," Federal Register, vol.58, no. 92, $28660-28734$.

U.S. General Services Administration, September, 1992, "Refrigerant Management Plan." 

APPENDIX A GSA Chiller Inventory sample Printout

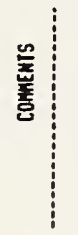

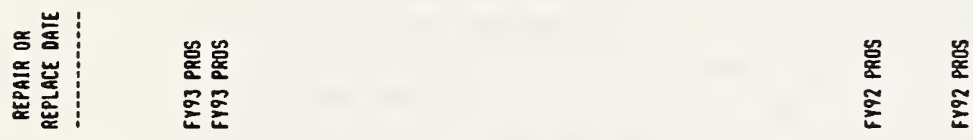

:

:

总

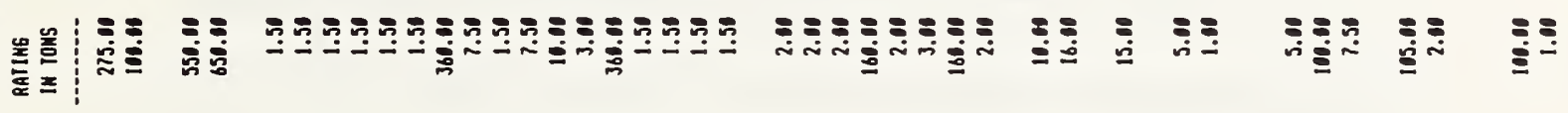

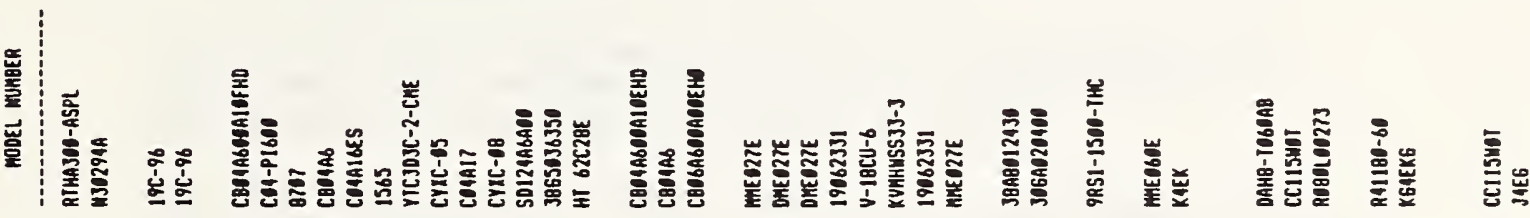

||

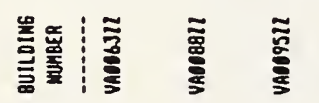

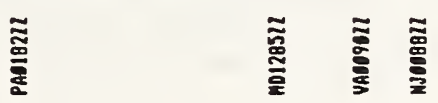

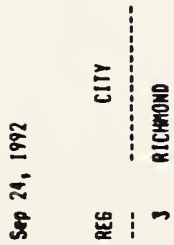

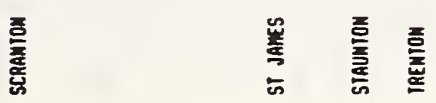

A - 1 



\section{APPENDIX B GSA "CFC SPECIFICATION"}

\section{CFC SPECIFICATION}

\section{General}

A. Effective July 1, 1992, the Environmental Protection Agency (EPA), as a part of the Clean Air Act of 1990, the London Amendments to the Montreal Protocol and other various directives, did prohibit the intentional discharge of venting of any Class I or Class II ozone depleting substances into the atmosphere. These substances are primarily chlorofluorocarbon (CFC) and hydrochloroflouro-carbon (HCFC) refrigerants.

Consequently, the Contractor shall take all steps necessary to recover, recycle, and store all CFC/HCFC refrigerants, regardless of source, whenever operations, maintenance, or repairs to Government equipment require, the recnvery/removal of CFC/HCFC refrigerants from equipment.

B. As a part of this contract, the Contractor shall receive as Government Furnished Property (see FAR 52.245-4) the following:

(1) The total of all on-site CFC/HCFC refrigerants.

(2) All containers/cylinders that are presently onsite and their contents.

(3) All previously maintained logs, records and inventories which provide the complete history of all currently on-site and/or in-use CFC/HCFC refrigerant.

It will be the responsibility of the Contractor to safeguard this documentation and to continue to maintain this program as detailed below.

C. The Contractor shall note that any permanently installed equipment retrofit necessary to further meet EPA requirements will be accomplished by GSA through other means and is not a part of this contract.

D. In the case of the disposal of an equipment item, (ie., window a/c unit, drinking water cooler, etc.), all CFC/HCFC refrigerants shall be recovered before any equipment is discarded.

Refrigerant recovered from an equipment item that is to be disposed of shall be considered to be contaminated. As such, this refrigerant must be reclaimed to it's ASHRE purity level before it can be used in any other equipment items. 
E. The Contractor shall provide for the acquisition and utilization of the appropriate size and type CFC/HCFC refrigerant recovery/recycling equipment systems, as well as provide the necessary personnel to properly and satisfactorily perform these requirements.

The Contractor may accomplish these requirements through either his own resources, or through a GSA approved subcontractor.

F. The Contractor shall, at the direction of the COR, process contaminated CFC/HCFC refrigerants through use of a EPA/ASHRE certified reclamation company, who shall guarantee the quality a-d purity of the reclaimed product. All costs associated with the reclamation of Government and be reimbursable to the Contractor.

The contractor shall follow all EPA, OSHA, ASHRAE and other Federal, State, or Local codes, regulations or guidelines as may now apply, or later become applicable, to these procedures.

\section{RECORDS MAINTENANCE}

The Contractor shall maintain a separate log (either existing or new) for each CFC/HCFC storage site under his/her responsibility. Establishment of CFC/HCFC storage sites shall be under the authority and direction of the COR. The appropriate forms/records/logs to be maintained shall be provided by the COR. Such documentation shall provide the following information:

A. Building name, address and number.

B. A listing of all equipment items containing CFC/HCFC refrigerants; the equipment item number; and the amount (pounds) of CFC/HCFC refrigerants contained within the equipment items.

C. The Identification Codes of all containers/cylinders belonging to that storage site.

D. The types and total amounts of all stored CFC/HCFC refrigerants on hand and exact storage location(s) wihtin the building.

E. The date of any recovery/recycling/reclaiming, or other utilization of CFC/HCFC refrigerants.

The location and ID number of the equipment item involved in the activity. 
F. The type and amount of CFC/HCFC refrigerants used per incident.

G. The type and amount of CFC refrigerants reclaimed; when reclaimed; who perfromed the service; and the cost involved.

All logs and records shall be keep on-site and shall be readily made available to the $C O R / C O$ upon request.

\section{STORAGE CONTAINERS/CYLINDERS}

A. The types, sizes and amounts of additional containers/ cylinders which may be required will be determined by GSA. The purchase of t:ese containers/cylinders shall be made by the contractor. The resulting costs shall be separately listed for each type of container/ cylinder and invoiced to GSA using the payment processing procedures fur additional sìrvices as specified elsewhere in these specifications.

B. The Contractor shall note that any additional storage containers/cylinders authorized for purchase by the $\mathrm{COR} / \mathrm{CO}$, or provided by the Government, will also become/remain Government Furnished Property. The Government reserves the right to furnish any additional containers/cylinders in lieu of Contractor purchase.

C. Containers/cylinders shall be limited in size to no more than a 125 lb capacity. They shall be stored in such a manner as to separate the refrigerants by type and whether the refrigerant is new, recovered, recycled, or reclaimed. Containers/cylinders shall be individually tagged as follows;

(1) Identification Code for records maintenance requirements.

(2) Type of CFC/HCFC refrigerants the container/ cylinder contains.

(3) Present amount contained in the container/ cylinder.

(4) Whether the CFC/HCFC refrigerants are new, recovered, recycled, or reclaimed and the date acquired.

(5) If containing recovered or recycled CFC/HCFC refrigerants, where from.

(6) Contaminated CFC/HCFC refrigerants, which have been recovered by the contractor and need to be reclaimed, shall be stored in separate containers/ 
cylinders and not mixed with any new or reusable refrigerants. The containers/cylinders shall be logged in and labeled as above and shall state the reason for the contamination (ie.. burn-out). The Contractor shall promptly notify the COR, so that proper GSA disposal/reclamation can be accomplished.

D. The Contractor shall maintain secured, on-site storage for all CFC/HCFC refrigerants in accordance with the Occupational Safety and Health Administration (OSHA) Regulations CFR 29 1910, parts 101 and 252, ASHRAE, ARI and other appropriate codes, regulations and guidelines as may apply. Container/cylinder storage locations shall be designated by the COR.

MISCELLANEOUS

The Contractor shall recognize that all CFC/HCFC refrigerants utilized in Government equipment and/or systems or located in government facilities; any CFC/HCFC refrigerants subsequently provided to the Contractor by the Government; any CFC/HCFC refrigerants provided by the Contractor while performing work under the terms of the contract, and any CFC/HCFC refrigerants recovered/recycled/reclaimed from Government equipment/systems, along with any purchased/ provided storage containers/cylinders, shall be and remain the property of the Government. As such, the Contractor shall maintain complete security over this property and shall keep, and make readily available for review, all records as outlined above.

Upon final expiration/termination of the Contract, the Contractor shall turn over all CFC/HCFC refrigerants, storage containers/cylinders and all original CFC/HCFC records to the COR or his/her designee. 
PART I, SECTION H:

10. Refrigerant Management Plan.

\section{a. Introduction:}

The Contractor shall comply with the provisions of the Clean Air Act, regulations promulgated by the Environmental Protection Agency (EPA), and GSA's Refrigerant Management Plan as they pertain tot he purchase, handling, record keeping and disposal of refrigerants and appliances which contain chlorine, or have an ozone depletion potential or global warming potential. A Facility Refrigerant Manager is available to provide assistance in determining the current requirements for refrigeration manageme.zt.

Pursuant to the Clean Air Act of 1990, the deliberate venting of Class I and Class II ozone-depleting substances into the atmciphere is expressly prohibited. These substances are primarily chlorofluorobarbon (CFC) and hydrochloroflourocarbon (HCFC) refrigerants. The contractor shall contain, recover, recycle, and reclaim these refrigerants such that only "deminimis" releases occur per EPA Rule 40 CFR Part 82 subpart F. This applies whenever operations, maintenance, or repairs to Government equipment are required and the potential exists for venting of these harmful substances.

\section{b. General:}

As part of this contract, the Contractor shall receive as Government Furnished Property:

(1) The total of all on-site CFC/HCFC refrigerants.

(2) All containers and cylinders presently in the inventory and their contents.

(3) All pre-existing maintenance records, logs, and inventories that provide the known history of all CFC/HCFC refrigerants.

The Contractor shall safeguard these documents and continue to maintain them as established in paragraph "c" below.

Any devices installed on or retrofitted to air conditioning and refrigeration equipment for the purpose of reducing the risk of refrigerant loss or as required by any future EPA regulation are the responsibility of GSA and is not a part of this contract.

Equipment that is necessary for the proper recovery and recycling of CFC and HCFC refrigerants is the responsibility of the contractor. This equipment shall be certified in accordance with EPA regulations (applies to equipment purchased after January 1 , 1993). It is further required that different types of 
refrigerants shall not be recovered into the same recovery equipment or containers in order to avoid cross-contamination of these refrigerants. The Contractor may accomplish these requirements himself, or through a qualified GSA approved subcontractor.

The Contractor shall comply with all relevant codes, regulations, and guidelines established by appropriate federal, state and local authorities, as well as industry. This includes, but is not necessarily limited to, the following:

(1) The Environmental Protection Agency (EPA).

(2) The Occupational Safety and Health Association (OSHA).

(3) The American Society of Heating, Refrigeration, and Air Conditioning Systems (ASHRAE).

\section{c. Records Maintenance:}

The Contractor shall maintain accurate records and logs of sufficient detail to track the usage of each refrigerant type on a monthly basis. the information needed is:

(1) Quantity purchased.

(2) Quantity in inventory.

(3) Quantity added to equipment.

(4) Used quantity to be disposed of or reclaimed.

(5) Quantity recovered from disposed equipment.

(6) Quantity reclaimed.

The Contractor shall maintain a separate log for each building covered by the contract and each type of refrigerant used in that building. Each form should record the building name, address, and building number. The following are the types of records which shall be kept.

(1) Refrigerant Inventory and Usage Log - Used to record transactions of all ozone-depleting refrigerants in inventory, to determine refrigerant requirements, and to identify refrigerant loss sources. It will track inventories on-hand, at a reclamation facility, and tqquantities disposed. Accidental losses may be recorded on this form. (Note: Refrigerants contained inside the equipment are not entered on this form.) Record who performed the services.

(2) Purge Unit Runtime Log - Used to record purge time on low pressure chillers and may provide some indication that excessive quantities of air are infiltrating the machine. This may be a separate $\mathrm{log}$, or included with (1) above. 
(3) Refrigerant OiI and Usage Log - Records transactions involving refrigerant lubricant usage.

(4) Individual Equipment Log for Refrigerant Accountability-Used to record the results of leak tests and the addition or removal of ozone depleting refrigerants form equipment. This form may be used to supplement the information in the Refrigerant Inventory and Usage Log in (1) above.

The Contractor may supplement these logs as appropriate. AlI logs and records shall be kept on site and be available to the CO/COR upon request.

\section{d. Refrigerant Storage Containers:}

The types, sizes and amounts of additional containers/cylinders which may be required will be determined by GSA. The purchase of these containers/cylinders shall be separately listed for each type of container/cylinder and invoiced to GSA using the payment processing procedures for additional services as specified elsewhere in this document. The Government reserves the right to furnish any additional containers/cylinders as Government Furnished Program in lieu of contractor purchase.

Containers/cylinders shall be limited in size to no more than a 125 lb capacity. They shall be stored in such a manner as to separate the refrigerants by type and whether the refrigerant is new or recovered. Containers/cylinders shall be individually tagged as follows:

(1) Identification Code for records maintenance requirements.

(2) Type of CFC/HCFC refrigerants the container/cylinder contains.

(3) Amount presently contained in the container/cylinder.

(4) Whether the CFC/HCFC refrigerants are new, recovered, or recycled, and the date acquired.

(5) If containing recovered.CFC/HCFC refrigerants, where they were recovered from.

(6) Contaminated CFC/HCFC refrigerants, which have been reclaimed by the contractor, shall be stored in separate containers/cylinders and not mixed with any new or reusable refrigerants. the containers/cylinders shall be logged in and labeled as above and shall also state the reason for the contamination (e.g., burn-out). The contractor shall also promptly notify the COR, so that proper GSA disposal can be accomplished. 
The Contractor shall maintain secured, on-site storage for all CFC/HCFC refrigerants in accordance with the occupational safety and Health Administration (OSHA) Regulations (29 CFR 1910) parts 101 and 252, ASHRAE, ARI and other appropriate codes, regulations and guidelines as may apply. Container/cylinder storage locations shall be designated by the COR.

\section{e. Miscellaneous:}

The Contractor shall recognize that all CFC/HCFC refrigerants utilized in Government equipment and/or systems or located in Government facilities, and any CFC/HCFC refrigerants recovered/reclaimed/recycled from Government equipment/systems, along with any purchased/provided storage containers/cylinders, are and shall remain the proparty of the Government. The Contractor shall maintain complete security over this property and shall keep, and make readily available for review, all records as outlined above.

Upon completion of the contract, the Contractor shall turn over all CFC/HCFC refrigerants, storage containers/cylinders and all original CFC/HCFC records to the COR or his/her designee. 

